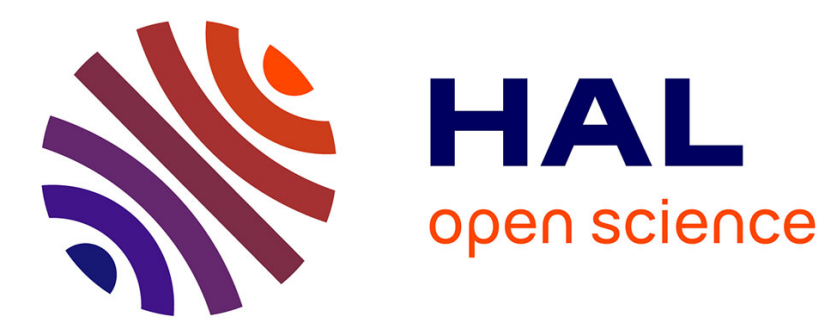

\title{
On the Political Economy of Free Trade
}

Rabah Amir, Hend Ghazzai, Rim Lahmandi-Ayed

\section{To cite this version:}

Rabah Amir, Hend Ghazzai, Rim Lahmandi-Ayed. On the Political Economy of Free Trade. 2020. hal-02506064

\section{HAL Id: hal-02506064 \\ https://hal.science/hal-02506064}

Preprint submitted on 12 Mar 2020

HAL is a multi-disciplinary open access archive for the deposit and dissemination of scientific research documents, whether they are published or not. The documents may come from teaching and research institutions in France or abroad, or from public or private research centers.
L'archive ouverte pluridisciplinaire HAL, est destinée au dépôt et à la diffusion de documents scientifiques de niveau recherche, publiés ou non, émanant des établissements d'enseignement et de recherche français ou étrangers, des laboratoires publics ou privés. 


\title{
On the Political Economy of Free Trade
}

\author{
Rabah Amir*
}

Hend Ghazzai ${ }^{\dagger}$

Rim Lahmandi-Ayed

March 12, 2020

\begin{abstract}
We consider a general equilibrium model with vertical preferences for one good and two identical countries each having initially one firm. Citizens in each country are asked to vote either for openness or for autarky. Openness means that a foreign firm can sell and produce its product in the domestic country and that the domestic firm can sell and produce its product in the foreign country. The decision to open frontiers is effective only when it is bilateral.

Citizens in each country are potentially consumers, workers and shareholders in the domestic firm. They differ with respect to their intensity of preference for quality and their sensitivity to effort.

The regime which will prevail between countries corresponds to the majority vote in the low quality country, as we prove that citizens in the high quality country always vote for openness. The outcome thus depends in a complex way on the degree of concentration of the ownership structure in the low quality country and the relative dispersion of the citizens with respect to their intensity of preference for quality and their sensitivity to effort.
\end{abstract}

Keywords: Globalization, Democracy, Vertical Preferences, General Equilibrium, Ownership Structure, Imperfect Competition.

JEL classification: L13, F16, D43

\footnotetext{
*Department of Economics, University of Iowa, Iowa City, IA 52242. Email: rabah-amir@ uiowa.edu

${ }^{\dagger}$ Mediterranean School of Business and Unité MASE-ESSAI, University of Carthage, e-mail: hend.ghazzai@msb.tn

†ESSAI and Unité MASE-ESSAI, University of Carthage, e-mail: rim.lahmandi@polytechnique.org, rim.lahmandi.ayed@gmail.com
} 


\section{Introduction}

Among the major policy issues faced by advanced democracies, free trade and its concomitant issues often form one of the most divisive and recurrent debates. Despite a long-standing consensus among economists that free trade is unambiguously welfare-improving, policy-makers and the public at large remain largely divided on issues of trade, labor migration, and firm relocation, or globalization, broadly construed.

For economists, the merits of free trade have been convincingly vindicated as Ricardo's original insights in favor of free trade under perfect competition have largely survived the passage to imperfect competition, barring significant asymmetries between countries. ${ }^{1}$ However, for society at large, higher social welfare need not translate into popular endorsement of free trade in cases where critical trade-related issues are decided upon via citizens' majority voting. As a case in point, BREXIT turned out to be a terrifying illustration of the ensuing potential for national crises. ${ }^{2}$ As to direct lessons that may be drawn from this recent history, the first would be that representative democracy where a social planner chosen by majority decides the best option, may diverge from direct participative democracy where citizens express their views directly. More broadly, a long-standing consensus reached on solid normative grounds need not translate into the right policy decision when positive elements of a political economy nature are taken into account. In particular, popular support for globalization may be far from unanimous even in countries with a long tradition of supporting free trade, such as Britain.

The existing imperfect competition models on globalization issues are partial equilibrium models with or without free entry, where a social planner takes the decision to open the borders to trade or not (see Footnote 1). Such models do not involve key issues related to wages, employment levels and possible labor migration. Yet, globalization may affect countries in a multi-faceted way, potentially impacting numerous sectors and individuals in a complex way. Another drawback is that, when it comes to modeling participative democracy such as the referendum on BREXIT, the adoption of a social planner representation is often of limited relevance.

In this paper, we introduce and solve a general equilibrium model in an international setting, where the decision to open the borders to full trade or not is taken within each country in a decentralized way, through a direct vote by a heterogeneous population. We consider two exante identical countries each having initially one firm. Each country is composed of individuals who are at the same time potential workers, consumers and shareholders of the domestic firm and differ with respect to their intensity of preference for quality and their labor ability. Firms may produce variants of a vertically differentiated product using labor as the unique input. Under autarky, each firm is a monopoly in its own country. Under open borders, firms may produce and sell their products in the foreign country. Thus they face competition but have access to larger product and labor markets. Firms set their qualities and prices non-cooperatively anticipating market clearing wages. Citizens in each country are asked to vote either for openness or autarky. Openness is effective only when a majority of citizens vote for this option in each country. Therefore, openness requires a favorable vote in both countries.

\footnotetext{
${ }^{1}$ An extensive literature has examined various facets of this issue: See e.g., Markusen (1981), Brander and Krugman (1983), Cordella (1993), Horstmann and Markusen (1992), Gabszewicz and Cordella (1997), Dong and Yuan (2010), Collie (2016), and Amir et al. (2017), among many others.

${ }^{2}$ Under pressure from the euro-sceptics even in his own party, David Cameron held an in-out referendum on the UK's EU membership. Despite the absolute majority of conservatives he obtained in the 2015 elections, BREXIT won the referendum in 2016. While BREXIT is currently under implementation, an earlier combination in 2005 of positive popular votes (in Spain and Luxembourg) and negative votes (in France and the Netherlands) led to a reframing of the proposed EU Constitution into the Lisbon Treaty.
} 
We thus consider a two-stage quality-price game in the tradition of vertical differentation models (Gabszewicz and Thisse, 1981, Shaked and Sutton, 1982, Lahmandi-Ayed, 2004), but with endogenous labor supply ${ }^{3}$. We prove that under autarky, both firms produce the highest possible quality. When economies are open, prices end up lower, wages are higher and the equilibrium at the quality stage of the game is such that one of the firms moves to a lower quality and gets a lower profit than under autarky while the profit of the high quality firm is higher under openness. Thus ex-ante identical countries turn into a high-quality country and a low-quality country via the natural Bertrand-type symmetry-breaking mechanism of endogenous product differentiation (Gabszewicz and Thisse, 1981, and Acemoglu et al., 2018). This asymmetry in product quality, and thus in concomitant labor wages and employment via the general equilibrium effects, often play a key role in real-life debates on trade issues.

On the political economy side, there are three effects that influence citizens' vote for or against openness. As consumers and/or workers, citizens prefer openness, as competition between firms offers more employment opportunities, lowers prices and increases wages. Thus the work/consumption effects favor openness. As shareholders, citizens may or not prefer autarky. Indeed, the ownership effect favors openness for the shareholders that own the highquality firm and favors autarky for the shareholders that own the low quality firm. There is no ownership effect for non-shareholders. The outcome of the vote thus depends on the relative weight of these effects. In the high quality country, citizens always vote for openness as the consumption, work and ownership effects all favor openness.

In the low quality country, non-shareholders always vote for openness as there is no ownership effect. Shareholders need to weigh the positive work/consumption effects against the negative ownership effect. The overall result of the votes in the low quality country depends in a complex way on the ownership structure and the dispersion of citizens with respect to their intensity of preference for quality and their sensitivity to effort. When non-shareholders form a majority, the outcome of the vote is for openness. When shareholders form a majority in that country, the majority vote may be for autarky or openness. The proportion of shareholders plays a double role. The higher this proportion, the higher the size of the population that may favor autarky as the ownership effect may outweigh the work/consumption effects. At the same time, the higher this proportion, the lower the share of each shareholder in the domestic firm's profit, the weaker the ownership effect. As individuals are assumed heterogeneous with respect to their preferences for quality and their sensitivity to effort, the work/consumption effects depend on individuals' intrinsic characteristics and may or not outweigh the ownership effect.

\section{Broader Related Literature:}

The present study adapts the model used in KLLL (2017) for a closed economy, to determine the outcome of a majority vote within the same country between two market structures: monopoly and duopoly. Only two extreme ownership structures were considered: concentrated ownership where the owners of the firms are negligible over the whole population, and egalitarian ownership where all citizens own equal shares in the firms. In the present paper, we consider an international version of this model where a proportion of the citizens own the domestic firm in each country. This proportion varies between 0 and 1 , which includes the two extreme cases, concentrated and egalitarian considered in KLLL (2017).

There is an extensive literature on international trade in a general equilibrium framework (Mosak, 1944, Krugman, 1979, Krugman, 1980, Dixit, 1984, Falvey and Kierzkowski, 1987,

\footnotetext{
${ }^{3}$ Hili, Lahmandi-Ayed and Lasram (2015, 2016) also consider endogenous labor supply in a vertical differentiation model but within a partial equilibrium setting.
} 
Chipman, 2012, among others). They examine trade in perfectly or imperfectly competitive markets and study the impact of trade policies such as tariffs on the equilibrium. They do not consider the decision to open or not frontiers.

An abundant literature exists on international trade and vertical differentiation. But to the best of our knowledge, the latter models do not deal with the decision to integrate or not nor base this decision on a decentralized mechanism. Whether using monopolistic competition (Baldwin and Harrigan, 2011, Fajgelbaum et al., 2011) or oligopolistic competition (Motta et al, 1997, Zhou et al., 2002, Petropoulou, 2013, Calmette et al., 2016), they derive comparative statics between autarky and trade equilibria in different contexts.

Last but not least, we review recent important empirical research on trade issues. Arkolakis et al. (2012) address the key issue of structural estimation of the gains from trade, and found that, based on a simplified method nesting many of the key existing models of trade, under perfect or monopolistic competition, trade delivers modest welfare gains. This work is not in direct relation to the present paper for two reasons: trade here means full economic integration, and our market structure is fully strategic. ${ }^{4}$ It is worth contrasting this with the reduced-form estimates of empirical researchers, which are much higher (e.g., Feyrer, 2009). Finally, using modern versions of the gravity model and various break-up counter-factual scenarios (all the way to reversion to WTO rules), Mayer et al. (2019) quantify the trade-related welfare gains each member country has reaped from the European Union, and report averages ranging from $3.8 \%$ to $5.5 \%$. This is of direct relevance to the present work, since free trade means full economic integration here, just as in the EU.

There are many empirical studies on the relationship between democracy and globalization. A first set of papers examine the effect of globalization on democracy: international trade has been shown to have a positive effect on democracy by Cordova and Meissner (2008) and Liu and Ornelas (2014); and a negative one by Li and Reuveny (2003). A second set of papers study the effect of democracy on international trade. The conclusions also diverge. Milner and Kubota (2005) and Krenz (2016) argue that democracy and political institutions have a positive impact on international trade. Instead, O'Rourke and Taylor (2006) and Yu (2007) show that democracy may have a negative impact on openness. Eichengreen and Leblang (2008) study the bidirectional causality between globalization and democracy. Their results suggest the existence of positive relationships running both ways between globalization and democracy.

The remainder of the paper is organized as follows. Section 2 describes the model and give some preliminary results corresponding to the equilibria under autarky and openness. Section 3 gives the results on the majority vote outcome. We conclude in section 4 . All proofs are given in Appendices A and B.

\section{Model And Preliminary Results}

We adopt an international version of the general equilibrium model first introduced by KLLL (2017). We consider two identical countries $(i=1,2)$ facing two options: (A) Autarky and (O) Openness. Each country $i$ has initially one firm $i$. There are 3 goods: a numeraire naturally available, labour as the unique input and a "differentiated" $[5$ good as the unique output. Firms produce the "differentiated" output using labor as the unique input, assuming that one unit of

\footnotetext{
${ }^{4}$ Interestingly, Krugman (1987) conjectured that the gains from trade should be higher in strategic, rather than perfectly competitive, settings.

${ }^{5}$ Differentiated in the sense that it may possibly be of different qualities perceived differently by consumers.
} 
the differentiated output requires one unit of labor (constant returns to scale).

Under autarky, each firm is a monopoly in its own country. It produces its output using the labor input of the domestic country and sells its product to the consumers of that country. If economies are open, a foreign firm can sell and produce its product in the domestic country and the domestic firm can sell and produce its product in the foreign country. Firms face competition and act in a duopoly structure but have access to a larger labor and good markets.

Citizens in each country are asked to vote either for autarky or openness. Openness is a bilateral choice i.e. openness occurs if and only if a majority of the population in each country vote for openness 6 Otherwise, autarky prevails.

In each country, there is a population of citizens who are potentially workers, consumers and shareholders. Each citizen is endowed with an indivisible unit of labor and a given quantity $e$ of a numeraire good. We denote by $\lambda \geq 0$ his/her share in the firm's profit.

Each citizen is characterized by his/her sensitivity to effort $\alpha \in[0, \bar{\alpha}]$ and his/her intensity of preference for the product's quality $\theta \in[0, \bar{\theta}]$. Citizens are uniformly distributed over $[0, \bar{\alpha}] \times[0, \bar{\theta}]$ with a density normalized to 1 .

Citizens derive their utility from the consumption of the differentiated product and the numeraire as follows :

$$
V(x, t)=\theta q x+t,
$$

where $x$ is the consumption of the differentiated product of exogenous quality $q, t$ is the consumption of the numeraire good. The consumption bundle $(x, t)$ belongs to the consumption set $\{0,1\} \times \mathbb{R}$, which implies that the differentiated good is indivisible.

A citizen has to choose sequentially whether to work or not and if so in which firm, and his/her consumption bundle.

If an individual $(\alpha, \theta)$ chooses to work in a firm producing quality $q$, he/she perceives a salary $(\omega)$ but must incur a training cost $\alpha q$, which is thus increasing with the produced quality and with the worker's type $\alpha$. This is why $\alpha$ is referred to as the sensitivity to effort of the individual. If he/she chooses not to work, he/she receives no wage (and does not have to be trained), his/her revenue being limited to the initial endowment in the numeraire and to his/her share in Firm $i$ 's profit.

Under autarky, in each country $i$, a citizen has the choice between remaining idle $(\bar{W})$ and working in the domestic firm $\left(W_{i}\right)$. Under openness, in each country $i$, a citizen has the choice to remain idle $(\bar{W})$, to work in the domestic firm $\left(W_{i}\right)$ and receive a wage $\omega_{i}$ or to work in the foreign firm $\left(W_{j}\right)$ and receive a wage $\omega_{j}$.

As for the consumption decision, each citizen has to decide whether to consume or not one unit of the differentiated product and in the positive from which firm. Under autarky, each citizen in country $i$ has to decide whether to buy or not the product of the domestic firm. Under openness, in each country $i$, a citizen has the choice not to consume $(\bar{C})$, consume the product of the domestic firm $\left(C_{i}\right)$ or the product of the foreign firm $\left(C_{j}\right)$.

\footnotetext{
${ }^{6}$ This is different from supposing that the openness decision is a cooperative one.
} 
In each country $i$, we suppose that the individuals are split into two groups: a uniform fraction $\mu_{i} \in[0,1]$ of the population are shareholders, with $\lambda=\frac{1}{\mu_{i} \overline{\bar{\alpha}}}$, and a fraction $1-\mu_{i}$ are non-owners, for whom $\lambda=0$. The lower $\mu_{i}$ the more concentrated is the ownership structure in country $i$ and the higher the share of each shareholder in the profit of Firm $i$. The higher $\mu_{i}$ the more egalitarian is the ownership structure and the lower the share of each shareholder in the profit of Firm $i$.

The decisions are taken as follows.

- First citizens in each country vote for Openness or Autarky.

- If the majority vote in at least one of the two countries is for Autarky, then autarky prevails. In this case, in each country, the domestic firm is a monopoly and chooses its quality $q \in[0, \bar{q}]$ and its price $p$.

- If in both countries, the majority vote is for Openness, then openness prevails. Then firms, having access to both markets (labour and output), play a standard two-step game where they choose first their qualities $q_{i}$ in the segment $[0, \bar{q}]$, then their prices $p_{i}$. The salaries adjust so as to balance demand and offer on the labour market.

To determine equilibrium under autarky and under openness, we proceed as in KLLL (2017). First we determine the firms' demands as function of prices, as in a standard vertical differentiation model. This gives at the same time the demand for labour (as one unit of product requires exactly one unit of labour). Then we determine the offer of labour for each firm as function of wages. Balancing offer and demand on the labor market, we express the wages as function of prices, which allows to express the profits as function of prices and qualities. Finally, we proceed by backward induction: calculation of prices then calculation of qualities.

Results 1 and 2 provide the equilibrium outcomes under autarky and openness. For completeness, some hints on the proofs are provided in Appendix A. Further details may be found in KLLL (2017). Indeed Result 1 is identical to the monopoly equilibrium in KLLL (2017). In Result 2, prices and qualities are the same as the duopoly equilibrium in KLLL (2017) but firms' profits under openness double as demands double.

Result 1 (Autarky Equilibrium). Under autarky, in each country $i(i=1,2)$, firm i produces quality $q_{A}^{*}=\bar{q}$ and sells it at price $p_{A}^{*}=\frac{\bar{\theta} \bar{q}(\bar{\theta}+2 \bar{\alpha})}{2(\bar{\theta}+\bar{\alpha})}$. Workers receive a wage $\omega_{A}^{*}=\frac{\bar{\alpha} \bar{\theta} \bar{q}}{2(\bar{\theta}+\bar{\alpha})}$ and the profit of firm $i$ is given by $\pi_{A}^{*}=\frac{\bar{\alpha} \bar{\theta}^{3} \bar{q}}{4(\bar{\theta}+\bar{\alpha})}$.

Result 2 (Openness Equilibrium). Under openness, assuming without loss of generality that $q_{1} \leq q_{2}$, at equilibrium qualities, prices, wages and profits are given by:

$$
\left\{\begin{array}{l}
q_{1}^{*}=\frac{4}{7} \bar{q}, \\
q_{2}^{*}=\bar{q} .
\end{array} ;\left\{\begin{array}{l}
p_{1}^{*}=\frac{\bar{\theta} \bar{q}(\bar{\theta}+8 \bar{\alpha})}{14(\bar{\theta}+\bar{\alpha})}, \\
p_{2}^{*}=\frac{\bar{\theta} \bar{q}(\bar{\theta}+4 \bar{\alpha})}{4(\bar{\theta}+\bar{\alpha})} .
\end{array} \quad ;\left\{\begin{array} { l } 
{ \omega _ { 1 } ^ { * } = \frac { \overline { \alpha } \overline { \theta } \overline { q } } { 2 ( \overline { \theta } + \overline { \alpha } ) } , } \\
{ \omega _ { 2 } ^ { * } = \frac { 3 \overline { \alpha } \overline { \theta } \overline { q } } { 4 ( \overline { \theta } + \overline { \alpha } ) } . }
\end{array} \quad \text { and } \left\{\begin{array}{l}
\pi_{1}^{*}=\frac{\bar{\alpha} \bar{\theta}^{3} \bar{q}}{24(\bar{\theta}+\bar{\alpha})}, \\
\pi_{2}^{*}=\frac{7 \bar{\alpha} \bar{\theta} \bar{q}}{24(\bar{\theta}+\bar{\alpha})} .
\end{array}\right.\right.\right.\right.
$$

In fact, there are two mirror equilibria where firms may play the reverse roles. We then select the equilibrium where Firm 1 is the low quality firm and Firm 2 is the high quality one. Somehow one of the countries has to specialize in low quality while the other has to specialize in high quality. Equivalently, there is no room under price competition for two firms producing the same quality. 


\section{To open or not to open}

We compare in Proposition 1 the outcomes of the equilibria under Autarky and Openness. The proof of Proposition 1 is omitted as it is obtained through simple comparisons using Results 1 and 2. Then we give the results on the majority vote outcome in both countries in Proposition 1 .

Lemma 1 (Comparison of the equilibria outcomes). Comparing the outcomes of equilibria obtained under autarky (Result 1) and openness (Result 2) and assuming without loss of generality that $q_{1} \leq q_{2}$, we have the following:

1. Wages: $\omega_{1}^{*}=\omega_{A}^{*}$ and $\omega_{2}^{*}>\omega_{A}^{*}$.

2. Price of the high quality: $p_{2}^{*}<p_{A}^{*}$.

3. Price Margins: $p_{1}^{*}-\omega_{1}^{*}<p_{2}^{*}-\omega_{2}^{*}<p_{A}^{*}-\omega_{A}^{*}$.

4. Firms' Demands: $D_{2}^{*}>D_{1}^{*}>D_{A}^{*}$.

5. Profits: $\pi_{1}^{*}<\pi_{A}^{*}$ and $\pi_{2}^{*}>\pi_{A}^{*}$.

6. Marginal Consumers: $0<\frac{p_{1}^{*}}{q_{1}^{*}}<\frac{p_{2}^{*}-p_{1}^{*}}{q_{2}^{*}-q_{1}^{*}}<\frac{p_{A}^{*}}{q_{A}^{*}}<\bar{\theta}$.

7. Marginal Workers: $0<\frac{\omega_{A}^{*}}{q_{A}^{*}}<\frac{\omega_{2}^{*}-\omega_{1}^{*}}{q_{2}^{*}-q_{1}^{*}}<\frac{\omega_{1}^{*}}{q_{1}^{*}}<\bar{\alpha}$.

Relative to autarky, openness adds on the market a new variant of the differentiated product and offers new working opportunities in both countries. The effects of openness on individuals are discussed based on the three potential roles of individuals.

1. Work effect: Under openness and due to competition between firms, a worker who chooses to work in the firm producing the low quality will receive the same wage as under autarky but will incur lower training costs. A worker who chooses to work in the firm producing the high quality will receive a higher wage than under autarky while incurring the same training cost. Therefore, as workers individuals are better off under openness than under autarky. When comparing marginal workers, openness increases the number of individuals who are willing to work. Indeed the number of workers in each country under autarky is $\bar{\theta} \frac{w_{A}}{q_{A}}$ while it is $\bar{\theta} \frac{w_{1}}{q_{1}}$ under openness. This is so because openness enlarges the opportunities offered to workers relative to autarky with better conditions.

2. Consumption effect: Under openness and due to competition between firms, a consumer will pay a lower price for the high quality than under autarky and has in addition the option of buying a lower quality variant of the product at a lower price. Therefore as consumers, individuals are better off under openness than under autarky; and openness increases the number of individuals who consume the differentiated product in each country. This number equals $\bar{\alpha}\left(\bar{\theta}-\frac{p_{A}}{q_{A}}\right)$ under autarky and $\bar{\alpha}\left(\bar{\theta}-\frac{p_{1}}{q_{1}}\right)$ under openness.

3. Shareholder (or ownership) effect: Examining the effect of openness on shareholders amounts to examine the effect of openness on profits. Openness increases both firms' demands as they have access to larger markets but reduces the price margins of both firms because of competition. The overall effect of openness is positive on the high quality firm's profit and negative on the low quality firm's profit. Therefore, as shareholders of the low quality firm, individuals are better off under autarky. As shareholders of the high quality firm, individuals are better off under openness. 
Lemma 2. We have the following.

1. In the high quality country (2), citizens always vote for Openness.

2. The regime which will prevail between the two countries (Autarky or Openness) corresponds to the majority vote in the low quality country (1).

From the equilibrium outcome under autarky and openness, the work and consumption effects always favor openness. The shareholder effect favors openness if the individual owns the high quality firm (thus belongs to Country 2 ) and favors autarky if the individual owns the low quality firm (thus belongs to Country 1).

In Country 2, the majority vote is always for openness as the work, consumption and shareholder effects all favor openness. As openness is effective only when both countries vote in majority for openness, openness will prevail if citizens in Country 1 vote in majority for this option.

Non-shareholders are always for openness as they perceive only the work and consumption effects which both favor openness. Hence, when non-shareholders are majority in Country 1 $\left(\mu_{1}<\frac{1}{2}\right)$, the majority vote in this country is for openness. When shareholders are majority in Country $1\left(\mu_{1}>\frac{1}{2}\right)$, we have to determine the choice of shareholders which results from the relative weight of positive work/consumption effects of openness and the negative shareholder effect.

We are now ready to provide Proposition 1 on the majority vote outcome in each country.

Proposition 1 (Votes' results). Whether Openness or Autarky prevails at equilibrium depends on the rate of shareholders in the low quality country $\left(\mu_{1}\right)$ and the relative dispersion of the intensity of preference for quality relative to the dispersion of sensitivity to effort $\left(\delta=\frac{\bar{\theta}}{\bar{\alpha}}\right)$, as depicted in Figure 1 in the space $\left(\mu_{1}, \delta=\frac{\bar{\theta}}{\bar{\alpha}}\right)$.

To determine the majority vote outcome in Country 1 when shareholders are majority, we have to determine the vote of each individual depending on the parameters and on his/her intrinsic characteristics $(\alpha, \theta)$. To do so, we have to identify the category of each individual in terms of work and consumption under each regime. Under Autarky equilibrium, each individual may be of 4 categories depending on whether he/she chooses to consume or not the differentiated good and to work or not. This divides $[0, \bar{\theta}] \times[@, \bar{\alpha}]$ into 4 zones. Under Openness equilibrium, the population is divided into 9 categories stemming from the choice of individuals between not consuming, consuming product 1 and consuming product 2 and the choice between not working, working in Firm 1 and working in Firm 2. Superimposing both divisions, leads to 16 areas that result from the relative position of the marginal workers and the marginal consumers under autarky and openness as given in Lemma 1 (See Figure 2). On each zone, the utility of each citizen under each regime (openness or autarky) is clearly identified. Then, we compare in each area and for each citizen $(\alpha, \theta)$ his/her utility under autarky and his/her utility under openness, which determines the vote of each citizen. We sum the number of citizens voting for each option. Finally, we compare the number of citizens who vote for either option with $\frac{1}{2} \bar{\alpha} \bar{\theta}$. This comparison depends on $\mu_{1}$ and $\delta=\frac{\bar{\theta}}{\bar{\alpha}}$ as given in Figure 1

In addition to the shareholder's characteristics $\alpha$ and $\theta$, the ownership parameter $\mu_{1}$ affects the results of the votes, playing a double role: (1) it determines the share in Firm 1's profit of 
each shareholder and (2) it represents the proportion of shareholders. It has thus two opposite effects on the vote outcome: (1) the higher $\mu_{1}$ the higher the proportion of shareholders i.e. the higher the number of citizens in country 1 who may potentially favor autarky because of the negative effect of openness on the profit but (2) the lower their share in firm 1's profit i.e. the less important is the negative shareholders' effect in the indirect utility function of shareholders.

Three openness zones appear in Figure 1, Zone "Openness 1" is characterized by a highly egalitarian ownership structure $\left(\mu_{1}>\frac{5}{6}\right)$ and comparable distributions of the citizens with respect to their intensity of preference for quality and their sensitivity to effort. Zone "Openness 2 " is characterized by a highly egalitarian ownership structure and a larger dispersion of individuals with respect to their intensities of preference for quality relative to their sensitivity to effort. Zone "Openness 3" is characterized by a less egalitarian ownership structure and a small $\delta$, i.e. a larger dispersion of citizens with respect to their sensitivity to effort relative to their intensities of preference for quality.

The majority vote outcome results on the one hand from the relative weight of the consumption/work and the shareholder effects, and on the other hand from the weight of each category of individuals in terms of consumption and work decisions under each regime over the whole population.

We first notice that shareholders who neither consume nor work when economies are open (Area 4 of Figure 2) will always vote for autarky due to the shareholder effect. The proportion of these citizens approaches 1 as $\delta$ approaches 0 . This is why for very small $\delta$ and any $\mu_{1}>\frac{1}{2}$ the majority vote is for autarky (areas under Openness 1 and Openness 3 zones on Figure 1 ).

As $\delta$ increases the weight of Area 4 diminishes. The citizens belonging no more to Area 4 necessarily change their working decision and/or consumption decision under openness. These individuals may potentially vote for openness. When the ownership structure is not highly egalitarian $\left(\mu_{1}<\frac{5}{6}\right.$ but remaining in the neighborhood of $\left.\frac{5}{6}\right)$, the shareholder effect is strong, thus the majority vote remains for autarky independently from $\delta$. When the ownership structure is highly egalitarian $\left(\mu_{1}>\frac{5}{6}\right)$, the shareholder effect is weaker as the shareholders' profit share is smaller and the majority vote is for openness for high enough $\delta$ (Openness 1 ) due to an increased weight of the citizens choosing to consume and/or work under openness.

As $\delta$ increases even more the majority vote shifts again from openness to autarky (Area just over Openness 1 zone). This is due to the fact that citizens in Area 1 of Figure 2 move all together from a vote for openness to a vote for autarky. Citizens in Area 1 work under both regimes in the high quality firm but do not consume. Their decision is thus not dependent on their intrinsic characteristics $\alpha$ and $\theta$ but on the wages and the profit shares received under each regime.

For very high $\delta$ and a highly egalitarian ownership structure $\left(\mu_{1}>\frac{5}{6}\right)$, citizens' votes shift again for openness (Openness 2). This is due to the fact that citizens make their choice mainly with respect to their consumption decision as they are much more dispersed with respect to their intensities of preference for quality. The proportion of individuals who consume the highest quality under both regimes (Areas 13, 14, 15 and 16, with a total weight on the whole population equal to $\left.\frac{\delta}{2(\delta+1)}\right)$ approaches $\frac{1}{2}$ when $\delta$ is very large. For these individuals the 
consumption effect outweighs the shareholder effect only when $\mu_{1}$ is sufficiently high. The majority vote is for autarky for high $\delta$ and low $\mu_{1}\left(\mu_{1}<\frac{5}{6}\right)$ because the shareholder effect is stronger and outweighs the consumption effect.

Finally, in Zone "Openness 3" , individuals are much more dispersed with respect to their sensitivity to effort than with respect to their preferences for quality and the shareholders' proportion $\mu_{1}$ is close to half. Zone "Openness 3" results from the vote for openness of all the non-shareholders and a subset of the shareholders. The shareholders preferring openness correspond to the individuals who take the decision to work in the high quality firm when economies are open (Areas 1, 2, 5, 6, 9, 10, 11 and 12 of Figure 2, with a total weight equal to $\left.\frac{7 \delta}{12(\delta+1)}\right)$ and therefore who from a working perspective prefer openness. These individuals (even if they are not numerous) and the non-shareholders whose proportion is close to half lead to a majority vote for openness.

As $\delta$ keeps increasing, the consumption decision becomes more important and some of these individuals switch their votes in favor of Autarky. Indeed citizens in Areas 1 and 2 (Figure 2) do not consume under both regimes, so have less reasons to vote for Openness. The result of the majority vote for high $\delta$ and $\mu_{1}$ close to half in then for Autarky. 


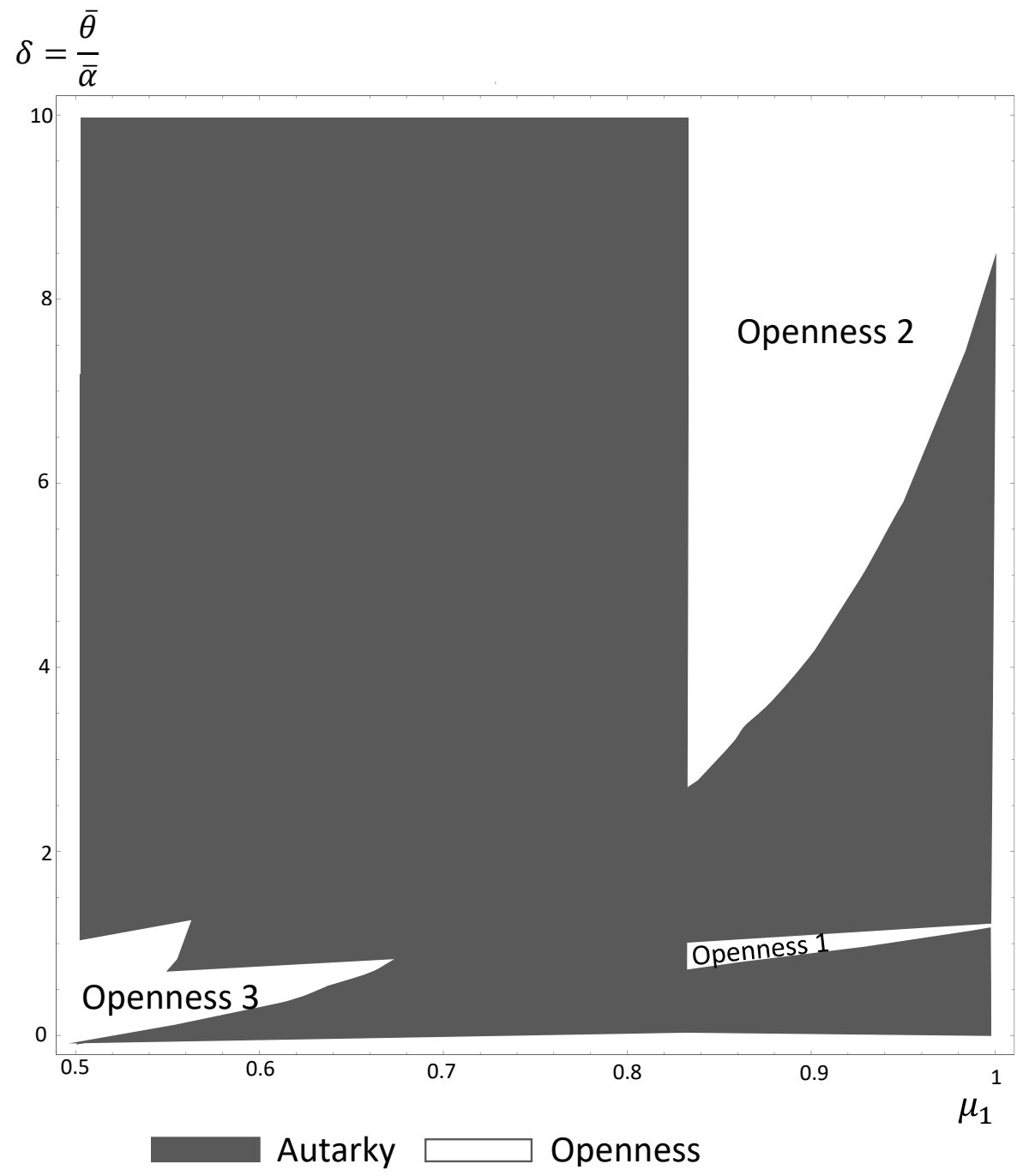

Figure 1 - Openness Zones in the $\left(\mu_{1}, \delta=\frac{\bar{\theta}}{\bar{\alpha}}\right)$-space. 


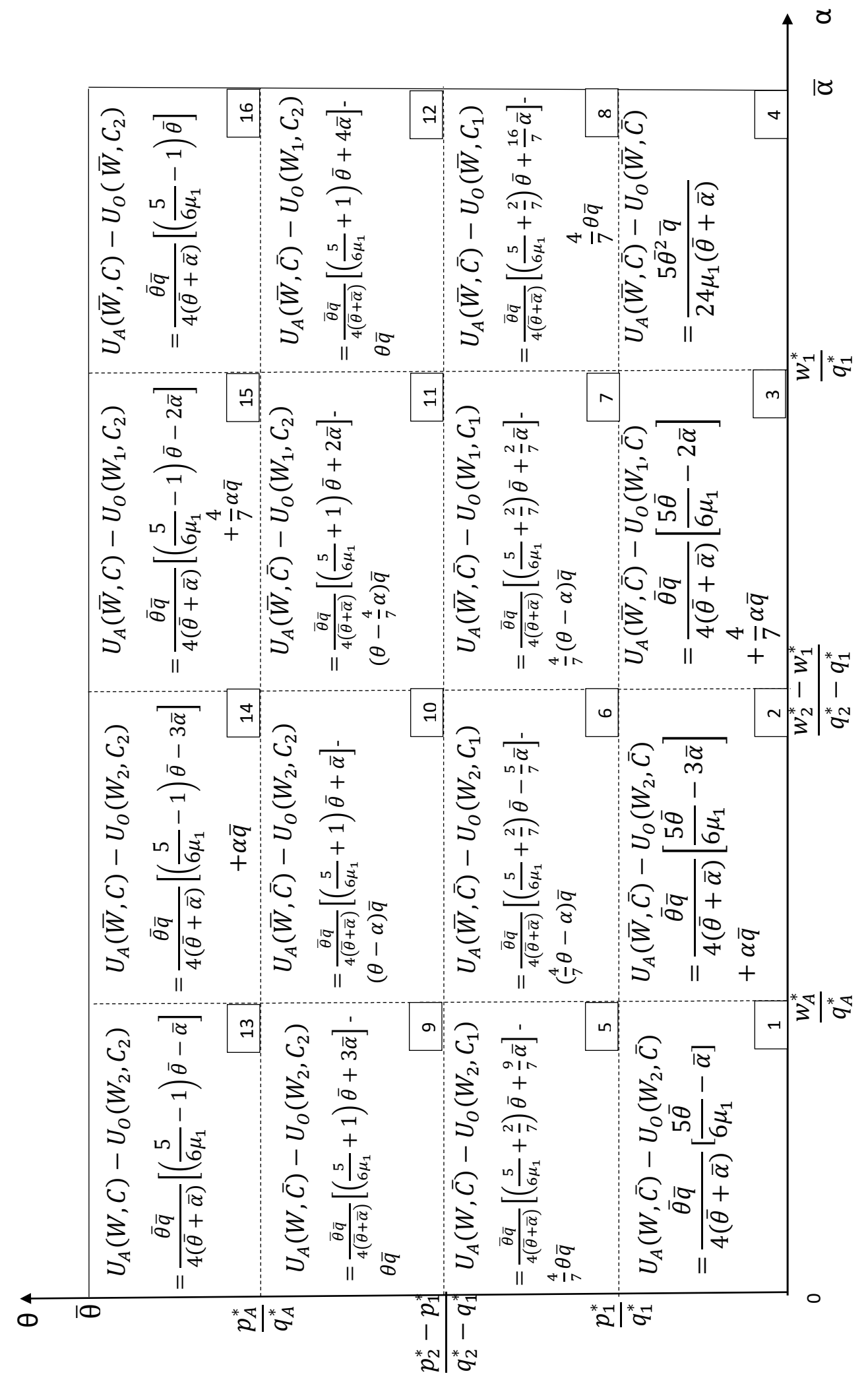

Figure 2 - Utilities differences $U_{A}-U_{O}$ in the space $(\alpha, \theta)$. 


\section{Conclusion}

Through a simple general equilibrium model where citizens are differentiated with respect to their preferences for quality and their sensitivity to effort, we examined the choice of countries to open to trade when this choice is made by a majority vote of the citizens. We determined the majority choice in both countries under different ownership structures of the economies. While citizens in the country of the high quality firm always vote for openness, the votes of the citizens in the other country depend on the ownership structure and the relative dispersion of the citizens with respect to their sensitivity to effort and their preferences for quality. The same model can be used to examine other economic issues such as education issues, development economics issues...

\section{References}

[1] Acemoglu, D., Robinson, J. and Verdier, T. (2017). Asymmetric Growth and Institutions in an Interdependent World. Journal of Political Economy, 125, 1245-1305.

[2] Amir, R., Jin, J. and Troege, M. (2017). Free Trade versus Autarky under Asymmetric Cournot Oligopoly. Review of International Economics, 25, 98-107.

[3] Arkolakis, C., Costinot, A. and Rodriguez-Clare A. (2012). New Trade Models, Same Old Gains. American Economic Review, 102(1), 94-130.

[4] Baldwin, R.E. and Harrigan, J. (2011). Zeros, Quality and Space: Trade Theory and Trade Evidence. American Economic Journal: Microeconomics, 3, 60-88.

[5] Brander, J. and Krugman, P. (1983). A 'Reciprocal Dumping' Model of International Trade. Journal of International Economics, 15, 313-321.

[6] Calmette, M.F., Kilkenny, M., Loustalan, C., Pechoux, I. and Bernard, C. (2016). A Model of International Trade with Vertical Differentiation and Stackelberg Leadership. TSE Working Papers 16-708, Toulouse School of Economics (TSE).

[7] Chipman, J.S. (2012). General Equilibrium and Welfare in International Trade. OEconomia [online], 2-1,15-33. URL:https://journal.openedition.org/oeconomia/1641.

[8] Choi, C.J. and Shin, H.S. (1992). A Comment on a Model of Vertical Product Differentiation. Journal of Industrial Economics, 40, 229-231.

[9] Collie, D.R. (2016). Gains from Variety? Product Differentiation and the Possibility of Losses from Trade under Cournot Oligopoly with Free entry. Economics Letters, 146, $55-58$.

[10] Cordella, T. (1993). Trade Liberalization and Oligopolistic Industries: A Welfare Appraisal. Louvain Economic Review, 59, 355-363.

[11] Cordova, J.E. and Meissner, C. (2008). The Impact of International Trade on Democracy: A Long Run Perspective. Worlds Politics, 60(4), 539-575. 
[12] Dixit, A. (1984). International Trade Policy for Oligopolistic Industries. Economic Journal, 94, 1-16.

[13] Dong, B. and Yuan, L. (2010). The Loss from Trade under International Cournot Oligopoly with Cost Asymmetry. Review of International Economics, 18, 818-831.

[14] Eichengreen, B. and Leblang, D. (2008). Democracy and Globalization. Economics \& Politics, 20, 289-334.

[15] Fajgelbaum, P., Grossman, G.M. and Helpman, E. (2011). Income Distribution, Product Quality, and International Trade. Journal of Political Economy, 119(4), 721-765.

[16] Falvey, R. and Kierzkowski, H. (1987). Product Quality, Intra-Industry Trade and (Im)perfect Competition, in: Kierzkowski (ed.). Protection and Competition in International Trade. New York [etc.] : Blackwell.

[17] Feyrer, J. (2009). Trade and Income: Exploiting Time Series in Geography. NBER Working Paper 14910.

[18] Flam, H. and Helpman, E. (1987). Vertical Product Differentiation and North-South Trade. American Economic Review, 77(5), 810-822.

[19] Gabszewicz, J-J. and Cordella T. (1997). Comparative Advantage under Oligopoly. Journal of International Economics, 43, 333-346.

[20] Gabszewicz, J-J. and Thisse J.F. (1981). Price Competition, Quality and Income Disparities. Journal of Economic Theory, 20(3), 340-359.

[21] Hili, A., Lahmandi-Ayed, R. and Lasram, H. (2015). Vertical Differentiation and Labor Market: the Differentiation Principle Revisited. Economics Bulletin, 35, 1.

[22] Hili, A., Lahmandi-Ayed, R. and Lasram, H. (2016). Differentiation, Labor market and Globalization. The Journal of International Trade and Economic Development, 25(6), 809-833.

[23] Horstmann, I.J. and Markusen, J.R. (1992). Endogenous Market Structures in International Trade (natura facit saltum). Journal of international Economics, 32, 109-129.

[24] Kahloul, A., Lahmandi-Ayed, R., Lasram, H. and Laussel D. (2017). Democracy and Competition: Vertical Differentiation and Labor in a General Equilibrium Model. Journal of Public Economic Theory, 19(4), 860-874.

[25] Krenz, A. (2016). Do Political Institutions Influence International Trade? Measurement of Institutions and the Long-Run Effects. Center for European, Governance and Economic Development Research Discussion Papers Number 276.

[26] Krugman, P. (1979). Increasing Returns, Monopolistic Competition and International Trade. Journal of International Economics, 9, 469-479.

[27] Krugman, P. (1980). Scale Economies, Product Differentiation and the Pattern of Trade. The American Economic Review, 70(5), 950-959.

[28] Krugman, P. (1987). Is Free Trade Passe?. Economic Perspectives, 1, 131-144. 
[29] Lahmandi-Ayed, R. (2004). Finiteness Property in Vertically Differentiated Markets: a Note on Locally Increasing and Decreasing Returns. Economic Theory, 23(2), 371-382.

[30] Li, Q. and Reuveny, R. (2003). Economic Globalization and Democracy: An Empirical Analysis. British Journal of Political Science, 33(1), 29-54.

[31] Liu, X. and Ornelas, E. (2014). Free Trade Agreements and the Consolidation of Democracy. American Economic Journal: Macroeconomics, 6(2), 29-70.

[32] Markusen, J.R. (1981). Trade and Gains from Trade with Imperfect Competition. Journal of International Economics, 11, 531-551.

[33] Mayer, T., Vicard, V. and Zignago, S. (2019). The Cost of Non-Europe, Revisited. Economic Policy, 34(98), 145-199.

[34] Milner, H., and Kubota, K. (2005). Why to Move to Free Trade? Democracy and Trade Policy in the Developing Countries. International Organization, 59(1), 107-143.

[35] Motta, M., Thisse, J., and Cabrales, A. (1997). On the Persistence of Leadership or Leapfrogging in International Trade. International Economic Review, 38(4), 809-824.

[36] Mozak, J.L. (1944). General Equilibrium Theory in International Trade., The Principia Press Inc, Bloomington Indiana.

[37] O'Rourke, K.H. and Taylor, A.M. (2006). Democracy and Protectionism. NBER Working Paper No. w12250.

[38] Petropoulou, D. (2013). Vertical Product Differentiation, Minimum Quality Standards, and International Trade. Oxford Economics Papers, 65(2), 372-393.

[39] Shaked, A. and Sutton, J. (1982). Relaxing Price Competition Through Product Differentiation. The Review of Economic Studies, 49(1), 3-13.

[40] Yu, M. (2007), Trade Globalization and Political Liberalization: A Gravity Approach. TIGER working paper No.104.

[41] Zhou, D., Spencer, B. and Vertinsky I. (2002). Strategic Trade Policy with Endogenous Choice of Quality and Asymmetric Costs. Journal of International Economics, 56(1), 205-232.

\section{Appendix A: Outline of the proofs of Results 1 and 2 .}

We proceed as in the proofs of Propositions 1 and 2 of KLLL (2017). Table 1 provides, in the case of monopoly, for each individual his/her consumption and working decisions and indirect utility, depending on his/her characteristics $(\alpha, \theta)$, the wage, the product's quality and price. 


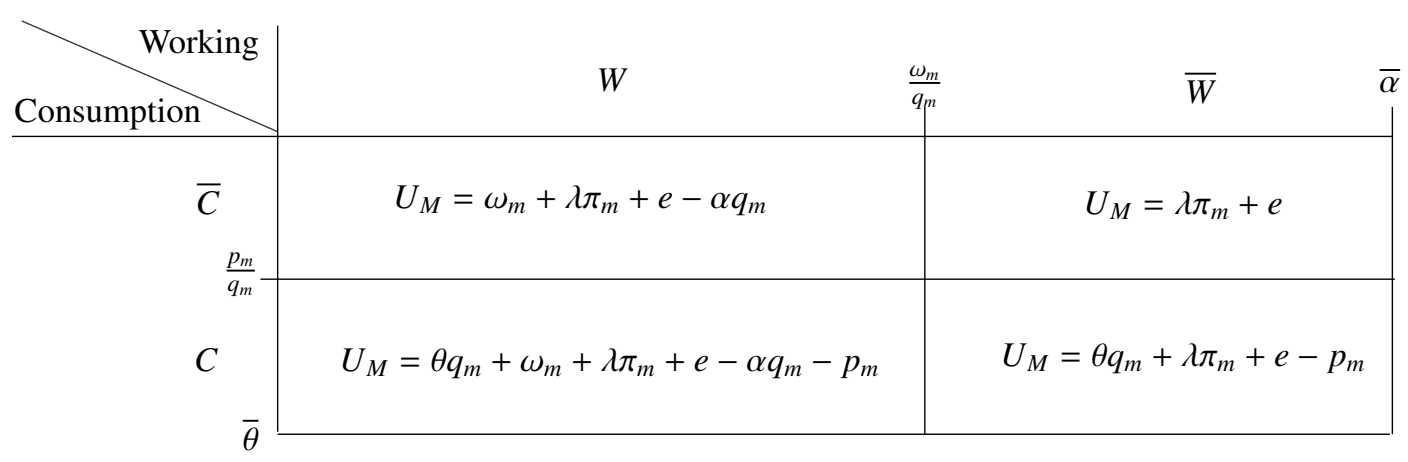

Table 1 - Consumption/working decisions and indirect utility $\left(U_{M}\right)$ of each individual in the monopoly case.

Due to the linearity of the utility function, the consumption decision depends only on $\theta$, the quality and the output price; and the working decision depends only on $\alpha$, the wage and the quality.

This allows to derive, in the case of monopoly, the labour supply in the differentiated sector: $\frac{\bar{\theta} \omega_{m}}{q_{m}}$ and the demand for the differentiated product: $\bar{\alpha}\left(\bar{\theta}-\frac{p_{m}}{q_{m}}\right)$.

The labour market clearing price is thus given by:

$\omega_{m}=\frac{\bar{\alpha}}{\bar{\theta}}\left(\bar{\theta} q_{m}-p_{m}\right)$. The profit is thus expressed as follows replacing the wage by the above expression: $\pi_{m}=\bar{\alpha}\left(p_{m}\left(1+\frac{\bar{\alpha}}{\bar{\theta}}\right)-\bar{\alpha} q_{m}\right)\left(\bar{\theta}-\frac{p_{m}}{q_{m}}\right)$.

The maximization of the profit w.r.t. price and quality yields the equilibrium outcome under monopoly in terms of price, quality, wage and profit of Result 1 .

In the duopoly case with $q_{1}<q_{2}$, Table 2 provides for each individual his/her consumption and working decisions and indirect utility, depending on his/her characteristics $(\alpha, \theta)$, on the wages, the products' qualities and prices. 


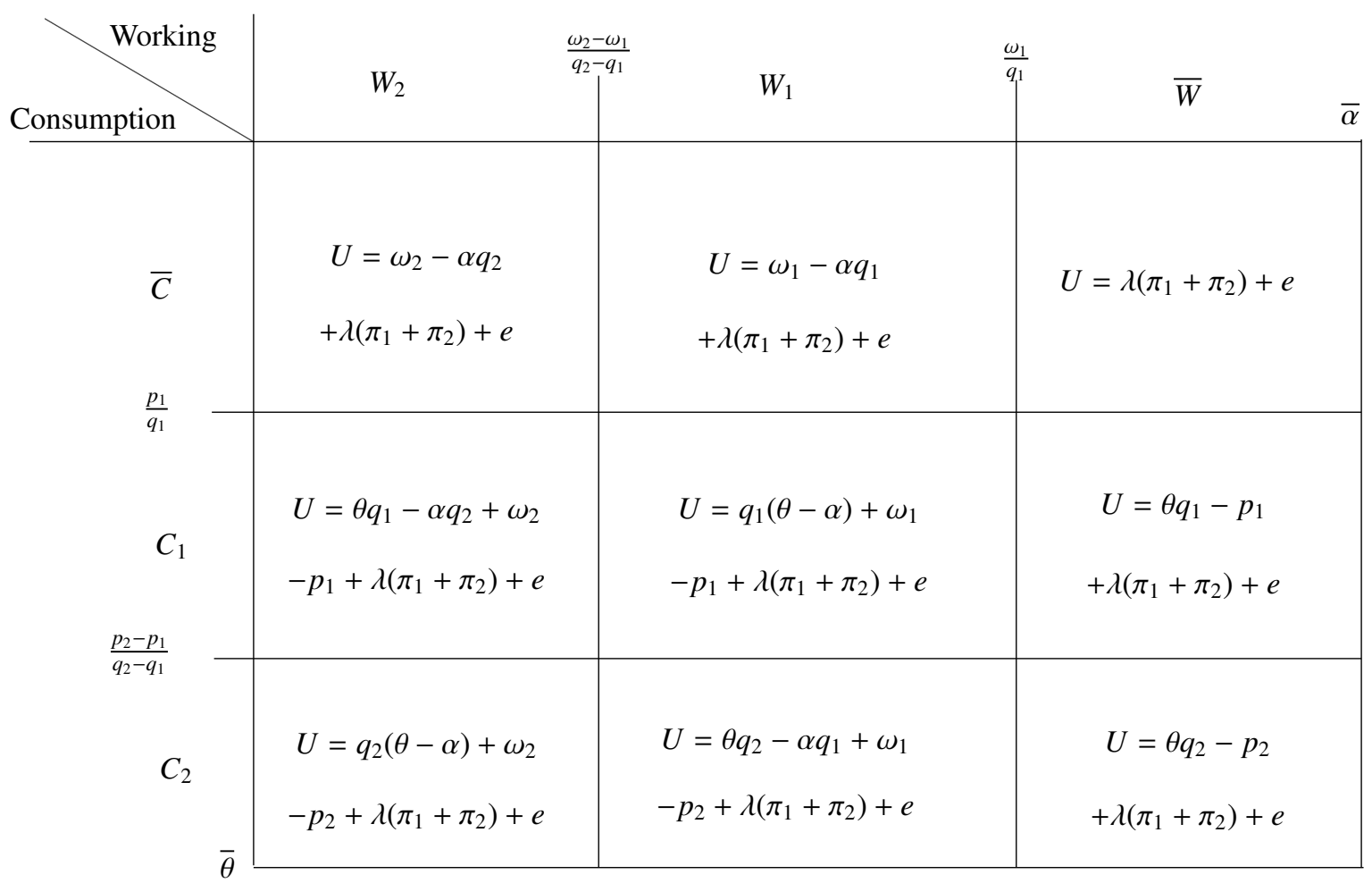

Table 2 - Consumption/working decisions and indirect utility $\left(U_{D}\right)$ of each individual in the duopoly case.

Thus the labour supplies for Firms 1 and 2 are respectively $\bar{\theta}\left(\frac{\omega_{1}}{q_{1}}-\frac{\omega_{2}-\omega_{1}}{q_{2}-q_{1}}\right)$ and $\bar{\theta}\left(\frac{\omega_{2}-\omega_{1}}{q_{2}-q_{1}}\right)$ and the demands for products of Firms 1 and 2 are respectively $\bar{\alpha}\left(\frac{p_{2}-p_{1}}{q_{2}-q_{1}}-\frac{p_{1}}{q_{1}}\right)$ and $\bar{\alpha}\left(\bar{\theta}-\frac{p_{2}-p_{1}}{q_{2}-q_{1}}\right)$.

Balancing offer and demand on the labor market yields:

$\omega_{1}=\bar{\alpha} q_{1}-\frac{\bar{\alpha}}{\bar{\theta}} p_{1}$ and $\omega_{2}=\bar{\alpha} q_{2}-\frac{\bar{\alpha}}{\bar{\theta}} p_{2}$.

Inserting the obtained expressions in the firms' profits given by ${ }^{7} ; \pi_{1}=2 \bar{\alpha}\left(p_{1}-\omega_{1}\right)\left(\frac{p_{2}-p_{1}}{q_{2}-q_{1}}-\right.$ $\left.\frac{p_{1}}{q_{1}}\right)$ and $\pi_{2}=2 \bar{\alpha}\left(p_{2}-\omega_{2}\right)\left(\bar{\theta}-\frac{p_{2}-p_{1}}{q_{2}-q_{1}}\right)$, and writing the F.O.C with respect to prices, we obtain the equilibrium prices as function of qualities. The we continue, inserting the equilibrium prices into the profits and maximizing w.r.t. qualities.

\section{Appendix B: Proof of Proposition 2}

The proof is divided in two parts:

- Part 1: We determine in each area described in Figure 2 which shareholders in country 1 vote for autarky and which shareholders vote for openness i.e. we study the sign of $U_{A}-U_{O}$. Different cases will appear depending on $\mu_{1}$ and $\delta=\frac{\bar{\theta}}{\bar{\alpha}}$.

- Part 2: We count the number of all citizens (shareholders and non shareholders) in country 1 who prefer openness and we determine the sign of the difference between this number and $\frac{1}{2} \bar{\theta} \bar{\alpha}$ which determines the results of the votes.

\section{Proof of Proposition 2: Part 1}

We determine the sign of $U_{A}-U_{O}$ given by Figure 2 in each of the sixteen areas:

\footnotetext{
${ }^{7}$ Here is the unique difference with the results obtained by KLLL (2017) in the duopoly case, as the profits double as demands double.
} 


\section{Area 1:}

$U_{A}-U_{O}<0$ implies $\delta<\frac{6}{5} \mu_{1}$.

\section{Area 2:}

$U_{A}-U_{O}<0$ is equivalent to $\alpha<\alpha_{2}$ where $\alpha_{2}=\frac{\bar{\theta}}{4(\bar{\theta}+\bar{\alpha})}\left(3 \alpha-\frac{5}{6 \mu_{1}} \bar{\theta}\right)$.

As in Area 2, $\frac{w_{A}^{*}}{q_{A}^{*}}<\alpha<\frac{w_{2}^{*}-w_{1}^{*}}{q_{2}^{*}-q_{1}^{*}}$, we have that $\alpha_{2}>\frac{w_{A}^{*}}{q_{A}^{*}}$ is equivalent to $\delta<\frac{6}{5} \mu_{1}$ and $\alpha_{2}<\frac{w_{2}^{*}-w_{1}^{*}}{q_{2}^{*}-q_{1}^{*}}$ is equivalent to $\delta>\frac{4}{5} \mu_{1}$. Three cases appear:

- if $\delta<\frac{4}{5} \mu_{1}$ then $\alpha_{2}>\frac{w_{2}^{*}-w_{1}^{*}}{q_{2}^{*}-q_{1}^{*}}$ and for all $\alpha$ in area $2, U_{A}-U_{O}<0$.

- if $\frac{4}{5} \mu_{1}<\delta<\frac{6}{5} \mu_{1}$ then $\frac{w_{A}^{*}}{q_{A}^{*}}<\alpha_{2}<\frac{w_{2}^{*}-w_{1}^{*}}{q_{2}^{*}-q_{1}^{*}}$. Thus, if $\alpha<\alpha_{2}, U_{A}-U_{O}<0$ and if $\alpha>\alpha_{2}$, $U_{A}-U_{O}>0$.

- if $\delta>\frac{6}{5} \mu_{1}$ then $\alpha_{2}<\frac{w_{A}^{*}}{q_{A}^{*}}$ and for all $\alpha$ in area $2, U_{A}-U_{O}>0$.

\section{Area 3:}

$U_{A}-U_{O}<0$ is equivalent to $\alpha<\alpha_{3}$ where $\alpha_{3}=\frac{7}{16} \frac{\bar{\theta}}{(\bar{\theta}+\bar{\alpha})}\left(2 \alpha-\frac{5}{6 \mu_{1}} \bar{\theta}\right)$.

As in Area 3, $\frac{w_{2}^{*}-w_{1}^{*}}{q_{2}^{*}-q_{1}^{*}}<\alpha<\frac{w_{1}^{*}}{q_{1}^{*}}$, we have that $\alpha_{3}>\frac{w_{2}^{*}-w_{1}^{*}}{q_{2}^{*}-q_{1}^{*}}$ is equivalent to $\delta<\frac{4}{5} \mu_{1}$ and we easily check that $\alpha_{3}<\frac{w_{1}^{*}}{q_{1}^{*}}$. Two cases appear:

- if $\delta<\frac{4}{5} \mu_{1}$ then $\frac{w_{2}^{*}-w_{1}^{*}}{q_{2}^{*}-q_{1}^{*}}<\alpha_{3}<\frac{w_{1}^{*}}{q_{1}^{*}}$. Thus, if $\alpha<\alpha_{3}, U_{A}-U_{O}<0$ and if $\alpha>\alpha_{3}$, $U_{A}-U_{O}>0$.

- if $\delta>\frac{4}{5} \mu_{1}$ then $\alpha_{3}<\frac{w_{2}^{*}-w_{1}^{*}}{q_{2}^{*}-q_{1}^{*}}$ and for all $\alpha$ in area $3, U_{A}-U_{O}>0$.

\section{Area 4:}

We easily check that in all area $4, U_{A}-U_{O}>0$.

\section{Area 5:}

$U_{A}-U_{O}<0$ is equivalent to $\theta>\theta_{5}$ where $\theta_{5}=\frac{\bar{\theta}}{16(\bar{\theta}+\bar{\alpha})}\left(9 \bar{\alpha}+\left[\frac{35}{6 \mu_{1}}+2\right] \bar{\theta}\right)$.

As in Area $5, \frac{p_{1}^{*}}{q_{1}^{*}}<\theta<\frac{p_{2}^{*}-p_{1}^{*}}{q_{2}^{*}-q_{1}^{*}}$, we have that $\theta_{5}>\frac{p_{1}^{*}}{q_{1}^{*}}$ is equivalent to $\delta>\frac{6}{5} \mu_{1}$ and $\theta_{5}<\frac{p_{2}^{*}-p_{1}^{*}}{q_{2}^{*}-q_{1}^{*}}$ is equivalent to $\delta>\frac{6 \mu_{1}}{5-4 \mu_{1}}$. We easily check that $\frac{6 \mu_{1}}{5-4 \mu_{1}}>\frac{6}{5} \mu_{1}$ for any $\mu_{1} \in\left[\frac{1}{2}, 1\right]$. Three cases appear:

- if $\delta<\frac{6}{5} \mu_{1}$ then $\theta_{5}<\frac{p_{1}^{*}}{q_{1}^{*}}$ and for all $\theta$ in area $5, U_{A}-U_{O}<0$.

- if $\frac{6}{5} \mu_{1}<\delta<\frac{6 \mu_{1}}{5-4 \mu_{1}}$ then $\frac{p_{1}^{*}}{q_{1}^{*}}<\theta_{5}<\frac{p_{2}^{*}-p_{1}^{*}}{q_{2}^{*}-q_{1}^{*}}$. Thus if $\theta<\theta_{5}, U_{A}-U_{O}>0$ and if $\theta>\theta_{5}$, $U_{A}-U_{O}<0$.

- if $\delta>\frac{6 \mu_{1}}{5-4 \mu_{1}}$ then $\theta_{5}>\frac{p_{2}^{*}-p_{1}^{*}}{q_{2}^{*}-q_{1}^{*}}$ and for all $\theta$ in area $5, U_{A}-U_{O}>0$.

\section{Area 6:}

$U_{A}-U_{O}<0$ is equivalent to $\theta>\frac{7}{4} \alpha+\frac{\bar{\theta}}{16(\bar{\theta}+\bar{\alpha})}\left[\bar{\theta}\left(\frac{35}{6 \mu_{1}}+2\right)-5 \bar{\alpha}\right]$.

Let us denote by $\Delta_{6}$ the straight line defined by the equation $\theta=\frac{7}{4} \alpha+\frac{\bar{\theta}}{16(\bar{\theta}+\bar{\alpha})}\left[\bar{\theta}\left(\frac{35}{6 \mu_{1}}+2\right)-5 \bar{\alpha}\right]$ in the space $(\alpha, \theta)$. To find the number of consumers who vote either for autarky or openness in area 6 , we need to study the intersections of the line $\Delta_{6}$ and the borders of area 6 . The borders of area 6 are defined by the two vertical lines $\alpha=\frac{w_{A}^{*}}{q_{A}^{*}}$ and $\alpha=\frac{w_{2}^{*}-w_{1}^{*}}{q_{2}^{*}-q_{1}^{*}}$ and the horizontal lines $\theta=\frac{p_{1}^{*}}{q_{1}^{*}}$ and $\theta=\frac{p_{2}^{*}-p_{1}^{*}}{q_{2}^{*}-q_{1}^{*}}$. 
The intersection point of $\Delta_{6}$ and the vertical line $\alpha=\frac{w_{A}^{*}}{q_{A}^{*}}$ is $\left(\frac{w_{A}^{*}}{q_{A}^{*}}, \frac{\bar{\theta}}{16(\bar{\theta}+\bar{\alpha})}\left[9 \bar{\alpha}+\bar{\theta}\left(\frac{35}{6 \mu_{1}}+2\right)\right]\right)$. From straightforward calculations the point $\left(\frac{w_{A}^{*}}{q_{A}^{*}}, \frac{\bar{\theta}}{16(\bar{\theta}+\bar{\alpha})}\left[9 \bar{\alpha}+\bar{\theta}\left(\frac{35}{6 \mu_{1}}+2\right)\right]\right)$ is above the line $\theta=\frac{p_{1}^{*}}{q_{1}^{*}}$ if and only if $\delta>\frac{6}{5} \mu_{1}$. It is below the line $\theta=\frac{p_{2}^{*}-p_{1}^{*}}{q_{2}^{*}-q_{1}^{*}}$ if and only if $\delta<\frac{6 \mu_{1}}{5-4 \mu_{1}}$.

The intersection point of $\Delta_{6}$ and the vertical line $\alpha=\frac{w_{2}^{*}-w_{1}^{*}}{q_{2}^{*}-q_{1}^{*}}$ is $\left(\frac{w_{2}^{*}-w_{1}^{*}}{q_{2}^{*}-q_{1}^{*}}, \frac{\bar{\theta}}{48(\bar{\theta}+\bar{\alpha})}\left[34 \bar{\alpha}+\bar{\theta}\left(\frac{35}{2 \mu_{1}}+6\right)\right]\right)$. From straightforward calculations the point $\left(\frac{w_{2}^{*}-w_{1}^{*}}{q_{2}^{*}-q_{1}^{*}}, \frac{\bar{\theta}}{48(\bar{\theta}+\bar{\alpha})}\left[34 \bar{\alpha}+\bar{\theta}\left(\frac{35}{2 \mu_{1}}+6\right)\right]\right)$ is above the line $\theta=\frac{p_{1}^{*}}{q_{1}^{*}}$ if and only if $\delta>\frac{4}{5} \mu_{1}$. It is below the line $\theta=\frac{p_{2}^{*}-p_{1}^{*}}{q_{2}^{*}-q_{1}^{*}}$ if and only if $\delta<\frac{4 \mu_{1}}{5-4 \mu_{1}}$.

As $\mu_{1}>\frac{1}{2}$, we have that $\frac{4}{5} \mu_{1}<\frac{6}{5} \mu_{1}<\frac{4 \mu_{1}}{5-4 \mu_{1}}<\frac{6 \mu_{1}}{5-4 \mu_{1}}$. Five cases appear as given by Figure 3 .
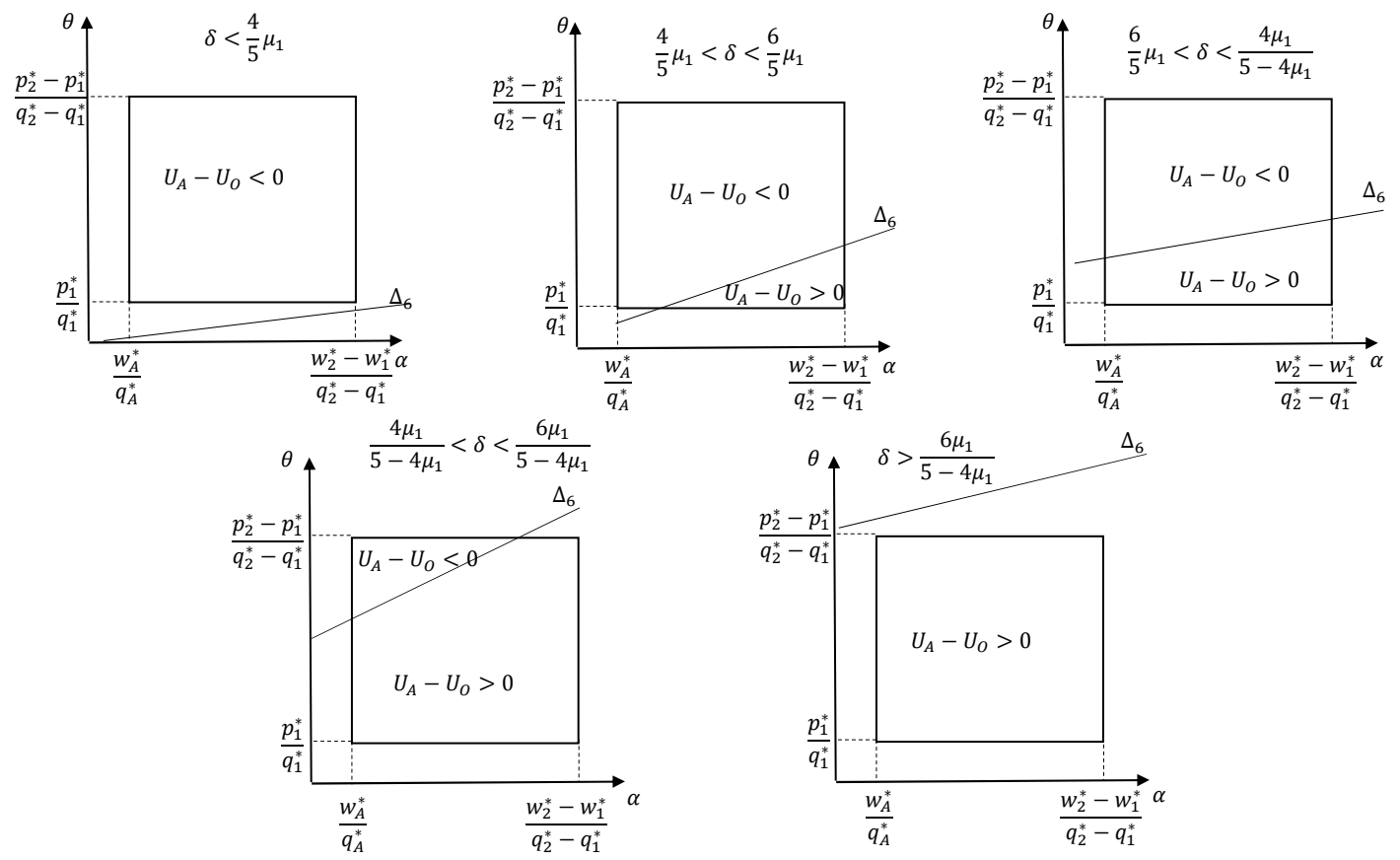

Figure 3 - Sign of $U_{A}-U_{O}$ in Area 6.

\section{Area 7:}

$U_{A}-U_{O}<0$ is equivalent to $\theta>\alpha+\frac{\bar{\theta}}{16(\bar{\theta}+\bar{\alpha})}\left[\bar{\theta}\left(\frac{35}{6 \mu_{1}}+2\right)+2 \bar{\alpha}\right]$.

Let us denote by $\Delta_{7}$ the straight line defined by the equation $\theta=\alpha+\frac{\bar{\theta}}{16(\bar{\theta}+\bar{\alpha})}\left[\bar{\theta}\left(\frac{35}{6 \mu_{1}}+2\right)+2 \bar{\alpha}\right]$ in the space $(\alpha, \theta)$. To find the number of consumers who vote either for autarky or openness in area 7, we need to study the intersections of the line $\Delta_{7}$ and the borders of area 7 . The borders of area 7 are defined by the two vertical lines $\alpha=\frac{w_{2}^{*}-w_{1}^{*}}{q_{2}^{*}-q_{1}^{*}}$ and $\alpha=\frac{w_{1}^{*}}{q_{1}^{*}}$ and the horizontal lines $\theta=\frac{p_{1}^{*}}{q_{1}^{*}}$ and $\theta=\frac{p_{2}^{*}-p_{1}^{*}}{q_{2}^{*}-q_{1}^{*}}$. 
The intersection point of $\Delta_{7}$ and the vertical line $\alpha=\frac{w_{2}^{*}-w_{1}^{*}}{q_{2}^{*}-q_{1}^{*}}$ is $\left(\frac{w_{2}^{*}-w_{1}^{*}}{q_{2}^{*}-q_{1}^{*}}, \frac{\bar{\theta}}{48(\bar{\theta}+\bar{\alpha})}\left[34 \bar{\alpha}+\bar{\theta}\left(\frac{35}{2 \mu_{1}}+6\right)\right]\right)$. From straightforward calculations the point $\left(\frac{w_{2}^{*}-w_{1}^{*}}{q_{2}^{*}-q_{1}^{*}}, \frac{\bar{\theta}}{48(\bar{\theta}+\bar{\alpha})}\left[34 \bar{\alpha}+\bar{\theta}\left(\frac{35}{2 \mu_{1}}+6\right)\right]\right)$ is above the line $\theta=\frac{p_{1}^{*}}{q_{1}^{*}}$ if and only if $\delta>\frac{4}{5} \mu_{1}$. It is below the line $\theta=\frac{p_{2}^{*}-p_{1}^{*}}{q_{2}^{*}-q_{1}^{*}}$ if and only if $\delta<\frac{4 \mu_{1}}{5-4 \mu_{1}}$.

The intersection point of $\Delta_{7}$ and the vertical line $\alpha=\frac{w_{1}^{*}}{q_{1}^{*}}$ is $\left(\frac{w_{1}^{*}}{q_{1}^{*}}, \frac{\bar{\theta}}{16(\bar{\theta}+\bar{\alpha})}\left[16 \bar{\alpha}+\bar{\theta}\left(\frac{35}{6 \mu_{1}}+2\right)\right]\right)$. From straightforward calculations the point $\left(\frac{w_{1}^{*}}{q_{1}^{*}}, \frac{\bar{\theta}}{16(\bar{\theta}+\bar{\alpha})}\left[16 \bar{\alpha}+\bar{\theta}\left(\frac{35}{6 \mu_{1}}+2\right)\right]\right)$ is always above the line $\theta=\frac{p_{2}^{*}-p_{1}^{*}}{q_{2}^{*}-q_{1}^{*}}$ and consequently above the line the $\theta=\frac{p_{1}^{*}}{q_{1}^{*}}$. Three cases appear as given by Figure 4 .

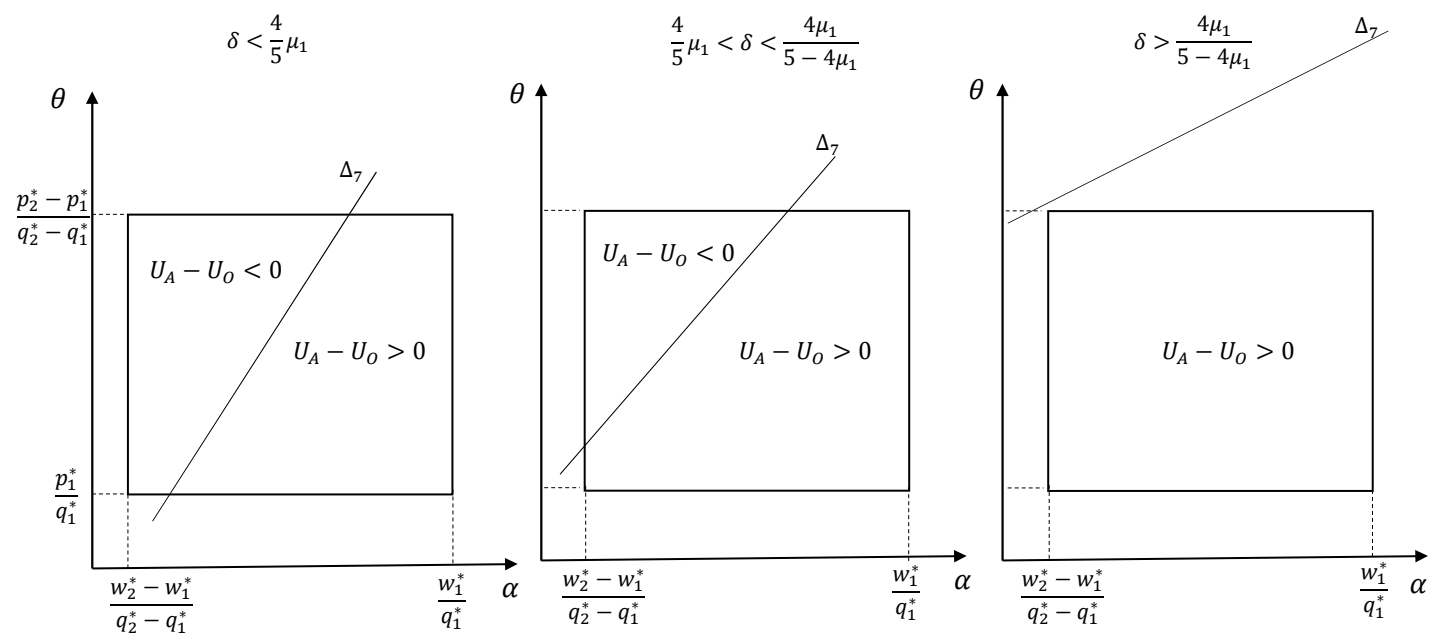

Figure $4-$ Sign of $U_{A}-U_{O}$ in Area 7.

\section{Area 8:}

$U_{A}-U_{O}<0$ is equivalent to $\theta>\theta_{8}$ where $\theta_{8}=\frac{\bar{\theta}}{16(\bar{\theta}+\bar{\alpha})}\left(16 \bar{\alpha}+\left[\frac{35}{6 \mu_{1}}+2\right] \bar{\theta}\right)$.

As in Area $8, \frac{p_{1}^{*}}{q_{1}^{*}}<\theta<\frac{p_{2}^{*}-p_{1}^{*}}{q_{2}^{*}-q_{1}^{*}}$, we easily check that $\theta_{8}>\frac{p_{2}^{*}-p_{1}^{*}}{q_{2}^{*}-q_{1}^{*}}>\frac{p_{1}^{*}}{q_{1}^{*}}$ and therefore $U_{A}-U_{O}>0$ for all $(\alpha, \theta)$ in Area 8 .

\section{Area 9:}

$U_{A}-U_{O}<0$ is equivalent to $\theta>\theta_{9}$ where $\theta_{9}=\frac{\bar{\theta}}{4(\bar{\theta}+\bar{\alpha})}\left(3 \bar{\alpha}+\left[\frac{5}{6 \mu_{1}}+1\right] \bar{\theta}\right)$.

As in Area 9, $\frac{p_{2}^{*}-p_{1}^{*}}{q_{2}^{*}-q_{1}^{*}}<\theta<\frac{p_{A}^{*}}{q_{A}^{*}}$, we have that $\theta_{9}>\frac{p_{2}^{*}-p_{1}^{*}}{q_{2}^{*}-q_{1}^{*}}$ is equivalent to $\delta>\frac{6 \mu_{1}}{5-4 \mu_{1}}$ and $\theta_{9}<\frac{p_{A}^{*}}{q_{A}^{*}}$ is equivalent to $\left(\frac{5}{6 \mu_{1}}-1\right) \bar{\theta}<\bar{\alpha}$. 
The inequality $\left(\frac{5}{6 \mu_{1}}-1\right) \bar{\theta}<\bar{\alpha}$ is always satisfied when $\mu_{1}>\frac{5}{6}$ and therefore $\theta_{9}<\frac{p_{A}^{*}}{q_{A}^{*}}$. When $\mu_{1}<\frac{5}{6}, \theta_{9}<\frac{p_{A}^{*}}{q_{A}^{*}}$ is equivalent to $\delta<\frac{6 \mu_{1}}{5-6 \mu_{1}}$. Different cases appear depending on $\mu_{1}$ and $\delta$.

- if $\mu_{1}>\frac{5}{6}$ then

- if $\delta<\frac{6 \mu_{1}}{5-4 \mu_{1}}$ then $U_{A}-U_{O}<0$ in all area 9.

- if $\delta>\frac{6 \mu_{1}}{5-4 \mu_{1}}$ then $U_{A}-U_{O}<0$ if $\theta>\theta_{9}$ and $U_{A}-U_{O}>0$ if $\theta<\theta_{9}$.

- if $\mu_{1}<\frac{5}{6}$ then

- if $\delta<\frac{6 \mu_{1}}{5-4 \mu_{1}}$ then $U_{A}-U_{O}<0$ in all area 9.

- if $\frac{6 \mu_{1}}{5-4 \mu_{1}}<\delta<\frac{6 \mu_{1}}{5-6 \mu_{1}}$ then $U_{A}-U_{O}<0$ if $\theta>\theta_{9}$ and $U_{A}-U_{O}>0$ if $\theta<\theta_{9}$.

- if $\delta>\frac{6 \mu_{1}}{5-6 \mu_{1}}$ then $U_{A}-U_{O}>0$ in all area 9.

\section{Area 10:}

$U_{A}-U_{O}<0$ is equivalent to $\theta>\alpha+\frac{\bar{\theta}}{4(\bar{\theta}+\bar{\alpha})}\left[\bar{\theta}\left(\frac{5}{6 \mu_{1}}+1\right)+\bar{\alpha}\right]$.

Let us denote by $\Delta_{10}$ the straight line defined by the equation $\theta=\alpha+\frac{\bar{\theta}}{4(\bar{\theta}+\bar{\alpha})}\left[\bar{\theta}\left(\frac{5}{6 \mu_{1}}+1\right)+\bar{\alpha}\right]$ in the space $(\alpha, \theta)$. To find the number of consumers who vote either for autarky or openness in area 10 , we need to study the intersections of the line $\Delta_{10}$ and the borders of area 10 . The borders of area 10 are defined by the two vertical lines $\alpha=\frac{w_{A}^{*}}{q_{A}^{*}}$ and $\alpha=\frac{w_{2}^{*}-w_{1}^{*}}{q_{2}^{*}-q_{1}^{*}}$ and the horizontal lines $\theta=\frac{p_{2}^{*}-p_{1}^{*}}{q_{2}^{*}-q_{1}^{*}}$ and $\theta=\frac{p_{A}^{*}}{q_{A}^{*}}$.

The intersection point of $\Delta_{10}$ and the vertical line $\alpha=\frac{w_{A}^{*}}{q_{A}^{*}}$ is $\left(\frac{w_{A}^{*}}{q_{A}^{*}}, \frac{\bar{\theta}}{4(\bar{\theta}+\bar{\alpha})}\left[3 \bar{\alpha}+\bar{\theta}\left(\frac{5}{6 \mu_{1}}+1\right)\right]\right)$. From straightforward calculations the point $\left(\frac{w_{A}^{*}}{q_{A}^{*}}, \frac{\bar{\theta}}{4(\bar{\theta}+\bar{\alpha})}\left[3 \bar{\alpha}+\bar{\theta}\left(\frac{5}{6 \mu_{1}}+1\right)\right]\right)$ is above the line $\theta=\frac{p_{2}^{*}-p_{1}^{*}}{q_{2}^{*}-q_{1}^{*}}$ if and only if $\delta>\frac{6 \mu_{1}}{5-4 \mu_{1}}$. It is below the line $\theta=\frac{p_{A}^{*}}{q_{A}^{*}}$ if and only if $\left(\frac{5}{6 \mu_{1}}-1\right) \bar{\theta}<\bar{\alpha}$.

The inequality $\left(\frac{5}{6 \mu_{1}}-1\right) \bar{\theta}<\bar{\alpha}$ is always satisfied when $\mu_{1}>\frac{5}{6}$ and therefore the point $\left(\frac{w_{A}^{*}}{q_{A}^{*}}, \frac{\bar{\theta}}{4(\bar{\theta}+\bar{\alpha})}\left[3 \bar{\alpha}+\bar{\theta}\left(\frac{5}{6 \mu_{1}}+1\right)\right]\right)$ is always below the horizontal line $\theta=\frac{p_{A}^{*}}{q_{A}^{*}}$. When $\mu_{1}<\frac{5}{6}$, the point $\left(\frac{w_{A}^{*}}{q_{A}^{*}}, \frac{\bar{\theta}}{4(\bar{\theta}+\bar{\alpha})}\left[3 \bar{\alpha}+\bar{\theta}\left(\frac{5}{6 \mu_{1}}+1\right)\right]\right)$ is below the horizontal line $\theta=\frac{p_{A}^{*}}{q_{A}^{*}}$ if and only if $\delta<\frac{6 \mu_{1}}{5-6 \mu_{1}}$.

The intersection point of $\Delta_{10}$ and the vertical line $\alpha=\frac{w_{2}^{*}-w_{1}^{*}}{q_{2}^{*}-q_{1}^{*}}$ is $\left(\frac{w_{2}^{*}-w_{1}^{*}}{q_{2}^{*}-q_{1}^{*}}, \frac{\bar{\theta}}{12(\bar{\theta}+\bar{\alpha})}\left[10 \bar{\alpha}+\bar{\theta}\left(\frac{5}{2 \mu_{1}}+3\right)\right]\right)$. From straightforward calculations the point $\left(\frac{w_{2}^{*}-w_{1}^{*}}{q_{2}^{*}-q_{1}^{*}}, \frac{\bar{\theta}}{12(\bar{\theta}+\bar{\alpha})}\left[10 \bar{\alpha}+\bar{\theta}\left(\frac{5}{2 \mu_{1}}+3\right)\right]\right)$ is above the line $\theta=\frac{p_{2}^{*}-p_{1}^{*}}{q_{2}^{*}-q_{1}^{*}}$ if and only if $\delta>\frac{4 \mu_{1}}{5-4 \mu_{1}}$. It is below the line $\theta=\frac{p_{A}^{*}}{q_{A}^{*}}$ if and only if $\left(\frac{5}{2 \mu_{1}}-3\right) \bar{\theta}<2 \bar{\alpha}$.

The inequality $\left(\frac{5}{2 \mu_{1}}-3\right) \bar{\theta}<2 \bar{\alpha}$ is always satisfied when $\mu_{1}>\frac{5}{6}$ and therefore the point $\left(\frac{w_{2}^{*}-w_{1}^{*}}{q_{2}^{*}-q_{1}^{*}}, \frac{\bar{\theta}}{12(\bar{\theta}+\bar{\alpha})}\left[10 \bar{\alpha}+\bar{\theta}\left(\frac{5}{2 \mu_{1}}+3\right)\right]\right)$ is always below the horizontal line $\theta=\frac{p_{A}^{*}}{q_{A}^{*}}$. When $\mu_{1}<\frac{5}{6}$, the point $\left(\frac{w_{2}^{*}-w_{1}^{*}}{q_{2}^{*}-q_{1}^{*}}, \frac{\bar{\theta}}{12(\bar{\theta}+\bar{\alpha})}\left[10 \bar{\alpha}+\bar{\theta}\left(\frac{5}{2 \mu_{1}}+3\right)\right]\right)$ is below the horizontal line $\theta=\frac{p_{A}^{*}}{q_{A}^{*}}$ if and only if $\delta<\frac{4 \mu_{1}}{5-6 \mu_{1}}$.

Different cases appear depending on $\mu_{1}$ and $\delta$.

- if $\mu_{1}>\frac{5}{6}$ then the sign of $U_{A}-U_{O}$ in area 10 is given by figure 5 .

- if $\mu_{1}<\frac{5}{6}$ then for any $\mu_{1} \in\left[\frac{1}{2}, \frac{5}{6}\right]$, we check that $\frac{4 \mu_{1}}{5-4 \mu_{1}}<\frac{6 \mu_{1}}{5-4 \mu_{1}}<\frac{4 \mu_{1}}{5-6 \mu_{1}}<\frac{6 \mu_{1}}{5-6 \mu_{1}}$. The sign of $U_{A}-U_{O}$ in area 10 is given by figure 6 . 


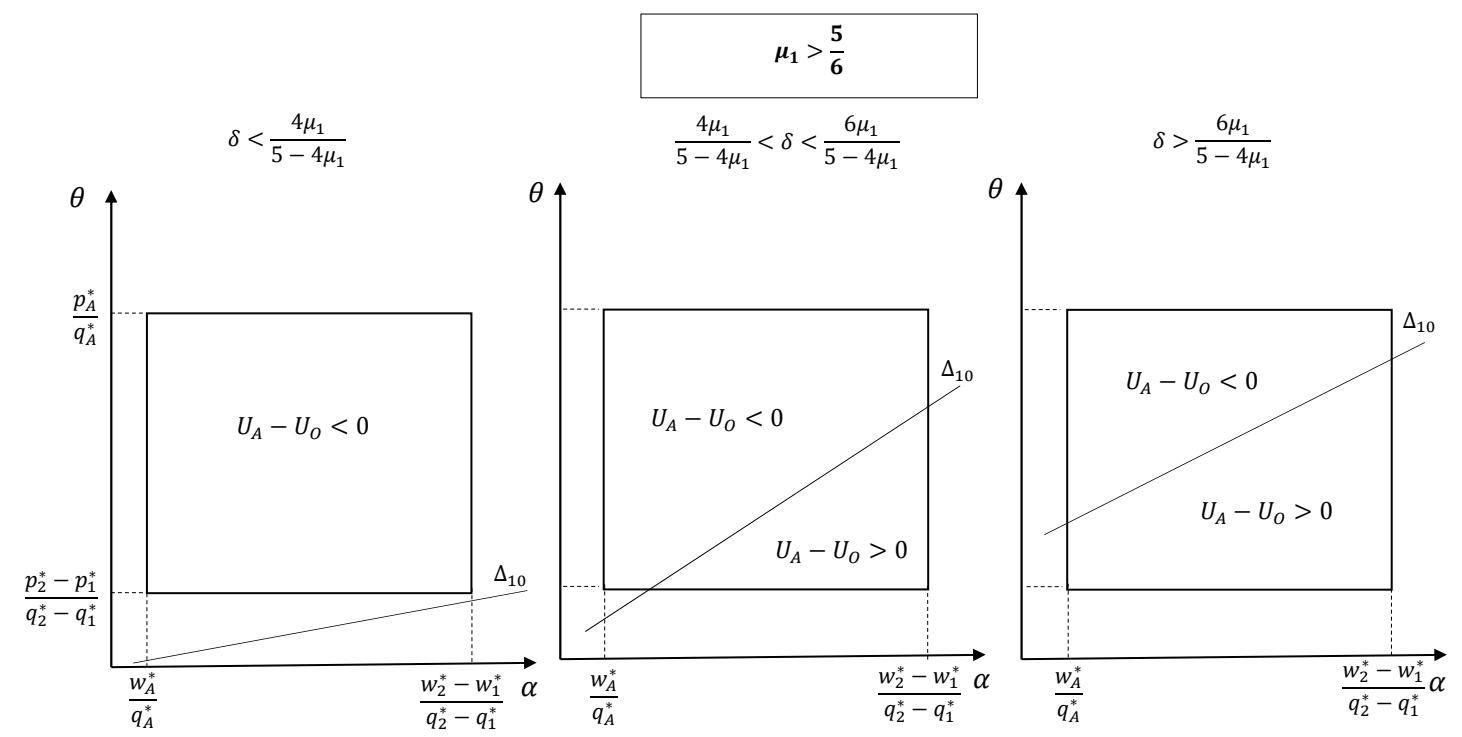

Figure $5-$ Sign of $U_{A}-U_{O}$ in Area 10 when $\mu_{1}>\frac{5}{6}$. 


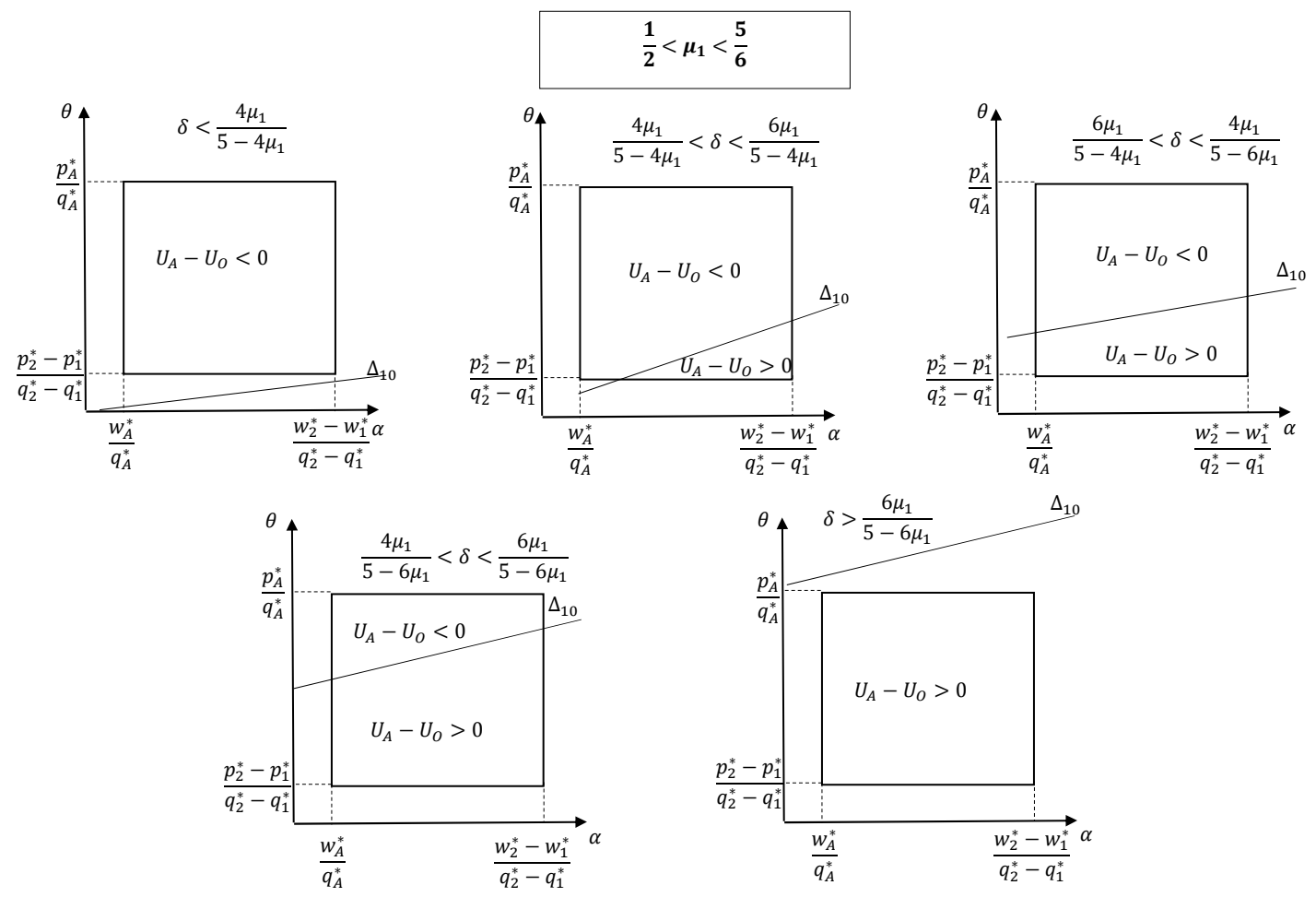

Figure $6-\operatorname{Sign}$ of $U_{A}-U_{O}$ in Area 10 when $\frac{1}{2}<\mu_{1}<\frac{5}{6}$.

\section{Area 11:}

$U_{A}-U_{O}<0$ is equivalent to $\theta>\frac{4}{7} \alpha+\frac{\bar{\theta}}{4(\bar{\theta}+\bar{\alpha})}\left[\bar{\theta}\left(\frac{5}{6 \mu_{1}}+1\right)+2 \bar{\alpha}\right]$.

Let us denote by $\Delta_{11}$ the straight line defined by the equation $\theta=\frac{4}{7} \alpha+\frac{\bar{\theta}}{4(\bar{\theta}+\bar{\alpha})}\left[\bar{\theta}\left(\frac{5}{6 \mu_{1}}+1\right)+2 \bar{\alpha}\right]$ in the space $(\alpha, \theta)$. To find the number of consumers who vote either for autarky or openness in area 11, we need to study the intersections of the line $\Delta_{11}$ and the borders of area 11 . The borders of area 11 are defined by the two vertical lines $\alpha=\frac{w_{2}^{*}-w_{1}^{*}}{q_{2}^{*}-q_{1}^{*}}$ and $\alpha=\frac{w_{1}^{*}}{q_{1}^{*}}$ and the horizontal lines $\theta=\frac{p_{2}^{*}-p_{1}^{*}}{q_{2}^{*}-q_{1}^{*}}$ and $\theta=\frac{p_{A}^{*}}{q_{A}^{*}}$.

The intersection point of $\Delta_{11}$ and the vertical line $\alpha=\frac{w_{2}^{*}-w_{1}^{*}}{q_{2}^{*}-q_{1}^{*}}$ is $\left(\frac{w_{2}^{*}-w_{1}^{*}}{q_{2}^{*}-q_{1}^{*}}, \frac{\bar{\theta}}{12(\bar{\theta}+\bar{\alpha})}\left[10 \bar{\alpha}+\bar{\theta}\left(\frac{5}{2 \mu_{1}}+\right.\right.\right.$ $3)])$. From straightforward calculations the point $\left(\frac{w_{2}^{*}-w_{1}^{*}}{q_{2}^{*}-q_{1}^{*}}, \frac{\bar{\theta}}{12(\bar{\theta}+\bar{\alpha})}\left[10 \bar{\alpha}+\bar{\theta}\left(\frac{5}{2 \mu_{1}}+3\right)\right]\right)$ is above the line $\theta=\frac{p_{2}^{*}-p_{1}^{*}}{q_{2}^{*}-q_{1}^{*}}$ if and only if $\delta>\frac{4 \mu_{1}}{5-4 \mu_{1}}$. It is below the line $\theta=\frac{p_{A}^{*}}{q_{A}^{*}}$ if and only if $\left(\frac{5}{2 \mu_{1}}-3\right) \bar{\theta}<2 \bar{\alpha}$. The inequality $\left(\frac{5}{2 \mu_{1}}-3\right) \bar{\theta}<2 \bar{\alpha}$ is always satisfied when $\mu_{1}>\frac{5}{6}$ and the point $\left(\frac{w_{2}^{*}-w_{1}^{*}}{q_{2}^{*}-q_{1}^{*}}, \frac{\bar{\theta}}{12(\bar{\theta}+\bar{\alpha})}\left[10 \bar{\alpha}+\bar{\theta}\left(\frac{5}{2 \mu_{1}}+3\right)\right]\right)$ is always below the line $\theta=\frac{p_{A}^{*}}{q_{A}^{*}}$. If $\mu_{1}<\frac{5}{6}$ then the point $\left(\frac{w_{2}^{*}-w_{1}^{*}}{q_{2}^{*}-q_{1}^{*}}, \frac{\bar{\theta}}{12(\bar{\theta}+\bar{\alpha})}\left[10 \bar{\alpha}+\bar{\theta}\left(\frac{5}{2 \mu_{1}}+3\right)\right]\right)$ is below the line $\theta=\frac{p_{A}^{*}}{q_{A}^{*}}$ if and only if $\delta<\frac{4 \mu_{1}}{5-6 \mu_{1}}$.

The intersection point of $\Delta_{11}$ and the vertical line $\alpha=\frac{w_{1}^{*}}{q_{1}^{*}}$ is $\left(\frac{w_{1}^{*}}{q_{1}^{*}}, \frac{\bar{\theta}}{4(\bar{\theta}+\bar{\alpha})}\left[4 \bar{\alpha}+\bar{\theta}\left(\frac{5}{6 \mu_{1}}+1\right)\right]\right)$. 
From straightforward calculations the point $\left(\frac{w_{1}^{*}}{q_{1}^{*}}, \frac{\bar{\theta}}{4(\bar{\theta}+\bar{\alpha})}\left[4 \bar{\alpha}+\bar{\theta}\left(\frac{5}{6 \mu_{1}}+1\right)\right]\right)$ is always above the line $\theta=\frac{p_{2}^{*}-p_{1}^{*}}{q_{2}^{*}-q_{1}^{*}}$. It is below the line $\theta=\frac{p_{A}^{*}}{q_{A}^{*}}$ if and only if $\mu_{1}>\frac{5}{6}$.

Different cases appear depending on $\mu_{1}$ and $\delta$ as given in figure 7 .
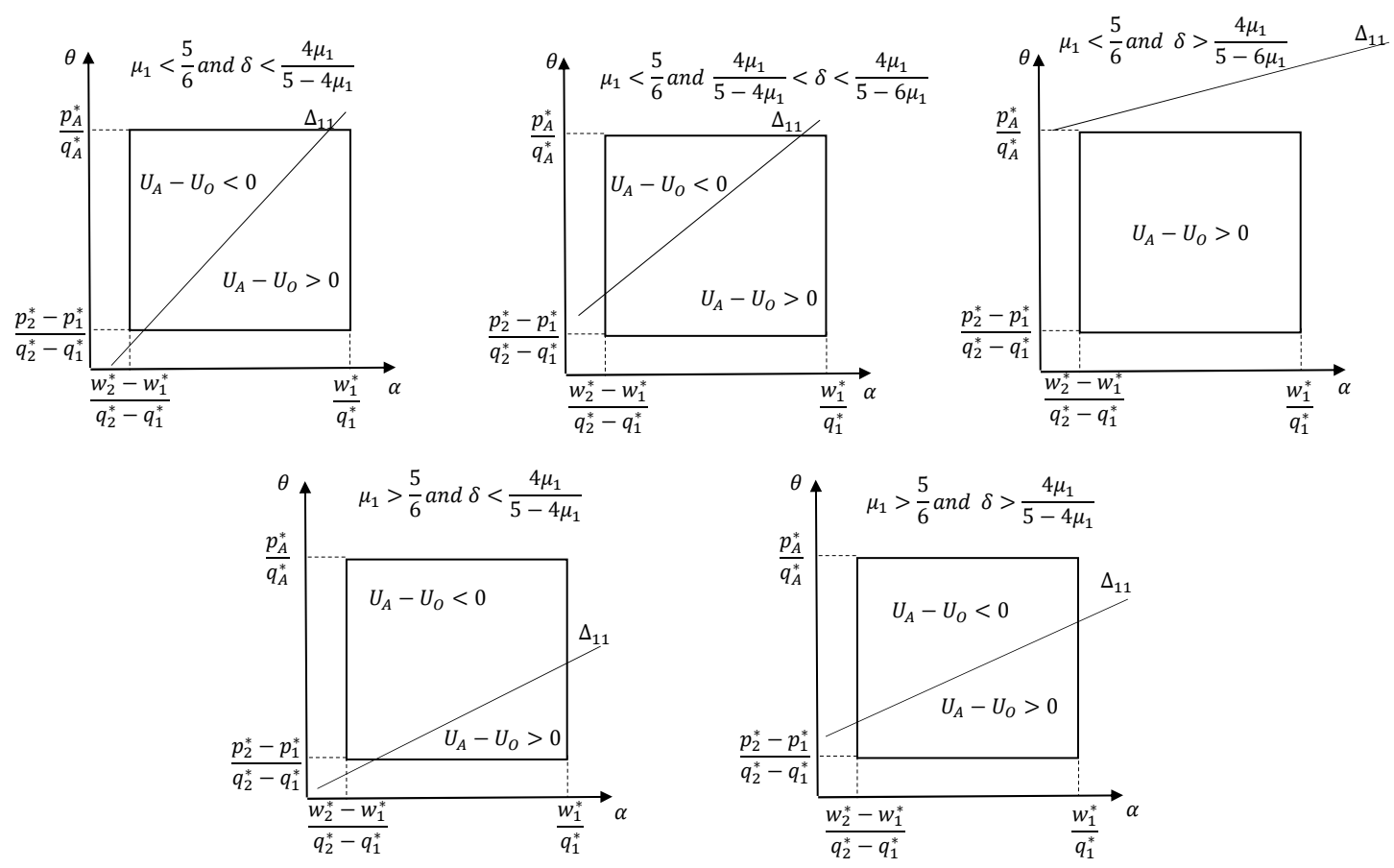

Figure 7 - Sign of $U_{A}-U_{O}$ in Area 11.

\section{Area 12:}

$U_{A}-U_{O}<0$ is equivalent to $\theta>\theta_{12}$ where $\theta_{12}=\frac{\bar{\theta}}{4(\bar{\theta}+\bar{\alpha})}\left[\bar{\theta}\left(\frac{5}{6 \mu_{1}}+1\right)+4 \bar{\alpha}\right]$.

As in Area 12, $\frac{p_{2}^{*}-p_{1}^{*}}{q_{2}^{*}-q_{1}^{*}}<\theta<\frac{p_{A}^{*}}{q_{A}^{*}}$, we easily check that $\theta_{12}>\frac{p_{2}^{*}-p_{1}^{*}}{q_{2}^{*}-q_{1}^{*}}$ and $\theta_{12}<\frac{p_{A}^{*}}{q_{A}^{*}}$ is equivalent to $\mu_{1}>\frac{5}{6}$.

Two cases appear depending on $\mu_{1}$.

- if $\mu_{1}>\frac{5}{6}$ then $\theta_{12}<\frac{p_{A}^{*}}{q_{A}^{*}}$ and $U_{A}-U_{O}<0$ if and only if $\theta>\theta_{12}$.

- if $\mu_{1}<\frac{5}{6}$ then $\theta_{12}>\frac{p_{A}^{*}}{q_{A}^{*}}$ and $U_{A}-U_{O}>0$ for all $(\alpha, \theta)$ in area 12 .

\section{Area 13:}

$U_{A}-U_{O}<0$ is equivalent to $\bar{\theta}\left(\frac{5}{6 \mu 1}-1\right)-\bar{\alpha}<0$. Therefore,

- if $\mu_{1}>\frac{5}{6}$ then $U_{A}-U_{O}<0$ for all $(\alpha, \theta)$ in area 13 . 
- if $\mu_{1}<\frac{5}{6}$ then $U_{A}-U_{O}<0$ if and only if $\delta<\frac{6 \mu_{1}}{5-6 \mu_{1}}$.

\section{Area 14:}

$U_{A}-U_{O}<0$ is equivalent to $\alpha<\alpha_{14}$ where $\alpha_{14}=\frac{\bar{\theta}}{4(\bar{\theta}+\bar{\alpha})}\left[\bar{\theta}\left(1-\frac{5}{6 \mu_{1}}\right)+3 \bar{\alpha}\right]$. As in area 14, $\frac{w_{A}^{*}}{q_{A}^{*}}<\alpha<\frac{w_{2}^{*}-w_{1}^{*}}{q_{2}^{*}-q_{1}^{*}}$, we check that $\alpha_{14}>\frac{w_{A}^{*}}{q_{A}^{*}}$ is always satisfied when $\mu_{1}>\frac{5}{6}$. If $\mu_{1}<\frac{5}{6}, \alpha_{14}>\frac{w_{A}^{*}}{q_{A}^{*}}$ is equivalent to $\delta<\frac{6 \mu_{1}}{5-6 \mu_{1}}$.

We also check that $\alpha_{14}>\frac{w_{2}^{*}-w_{1}^{*}}{q_{2}^{*}-q_{1}^{*}}$ is always satisfied when $\mu_{1}>\frac{5}{6}$ and is equivalent to $\delta<\frac{4 \mu_{1}}{5-6 \mu_{1}}$ if $\mu_{1}<\frac{5}{6}$. Different cases appear depending on $\mu_{1}$ and $\delta$ :

- if $\mu_{1}>\frac{5}{6}$ then $U_{A}-U_{O}<0$ for all $(\alpha, \theta)$ in area 14 .

- if $\mu_{1}<\frac{5}{6}$ then

- if $\delta<\frac{4 \mu_{1}}{5-6 \mu_{1}}$ then $U_{A}-U_{O}<0$ for all $(\alpha, \theta)$ in area 14.

- if $\frac{4 \mu_{1}}{5-6 \mu_{1}}<\delta<\frac{6 \mu_{1}}{5-6 \mu_{1}}$ then $U_{A}-U_{O}<0$ if and only if $\alpha<\alpha_{14}$.

- if $\delta>\frac{6 \mu_{1}}{5-6 \mu_{1}}$ then $U_{A}-U_{O}<0$ for all $(\alpha, \theta)$ in area 14 .

\section{Area 15:}

$U_{A}-U_{O}<0$ is equivalent to $\alpha<\alpha_{15}$ where $\alpha_{15}=\frac{7 \bar{\theta}}{8(\bar{\theta}+\bar{\alpha})}\left[\bar{\theta}\left(1-\frac{5}{6 \mu_{1}}\right)+2 \bar{\alpha}\right]$. As in area 15, $\frac{w_{2}^{*}-w_{1}^{*}}{q_{2}^{*}-q_{1}^{*}}<\alpha<\frac{w_{1}^{*}}{q_{1}^{*}}$, we check that $\alpha_{15}>\frac{w_{2}^{*}-w_{1}^{*}}{q_{2}^{*}-q_{1}^{*}}$ is always satisfied when $\mu_{1}>\frac{5}{6}$. If $\mu_{1}<\frac{5}{6}$, $\alpha_{15}>\frac{w_{2}^{*}-w_{1}^{*}}{q_{2}^{*}-q_{1}^{*}}$ is equivalent to $\delta<\frac{4 \mu_{1}}{5-6 \mu_{1}}$.

We also check that $\alpha_{15}>\frac{w_{1}^{*}}{q_{1}^{*}}$ is equivalent to $\mu_{1}>\frac{5}{6}$. Different cases appear depending on $\mu_{1}$ and $\delta$ :

- if $\mu_{1}>\frac{5}{6}$ then $U_{A}-U_{O}<0$ for all $(\alpha, \theta)$ in area 15.

- if $\mu_{1}<\frac{5}{6}$ then

- if $\delta>\frac{4 \mu_{1}}{5-6 \mu_{1}}$ then $U_{A}-U_{O}>0$ for all $(\alpha, \theta)$ in area 15.

- if $\delta<\frac{4 \mu_{1}}{5-6 \mu_{1}}$ then $U_{A}-U_{O}<0$ if and only if $\alpha<\alpha_{15}$.

\section{Area 16:}

$U_{A}-U_{O}<0$ is equivalent to $\mu_{1}>\frac{5}{6}$.

\section{Proof of Proposition 2: Part 2}

In this part, we sum the number of citizens (shareholders+ non-shareholders) in country 1 who will vote for an open economy and check whether these voters represent a majority. Twelve cases have to be discussed depending on $\mu_{1}$ and $\delta$ as found in the first part of the proof. We give in each case the difference between the number of citizens who prefer an open economy and $\frac{1}{2} \bar{\theta} \bar{\alpha}$ and we draw in the space $\left(\mu_{1}, \delta\right)$, the autarky zones (negative sign of the difference) and the openness zones (positive sign of the difference). This is how we obtain Figure 1.

Case 1: $\mu_{1}>\frac{5}{6}$ and $\delta<\frac{4}{5} \mu_{1}$

$D_{1}=\frac{\bar{\theta} \bar{\alpha}^{3}}{4608(\bar{\alpha}+\bar{\theta})^{2}}\left[2304 \mu_{1}\left(1-2 \mu_{1}\right)+192 \mu_{1}\left(19-9 \mu_{1}\right) \delta+72 \mu_{1}\left(7-2 \mu_{1}\right) \delta^{2}-7\left(25+60 \mu_{1}-12 \mu_{1}^{2}\right) \delta^{3}\right]$ 
Case 2: $\mu_{1}>\frac{5}{6}$ and $\frac{4}{5} \mu_{1}<\delta<\frac{6}{5} \mu_{1}$

$D_{2}=\frac{\bar{\theta} \bar{\alpha}^{3}}{18432 \mu_{1}(\bar{\alpha}+\bar{\theta})^{2}}\left[9216 \mu_{1}\left(1-2 \mu_{1}\right)+48 \mu_{1}\left(304-185 \mu_{1}\right) \delta+24 \mu_{1}\left(169-36 \mu_{1}\right) \delta^{2}-\left(175+1320 \mu_{1}-336 \mu_{1}^{2}\right) \delta^{3}\right]$

Case 3: $\mu_{1}>\frac{5}{6}$ and $\frac{6}{5} \mu_{1}<\delta<\frac{4 \mu_{1}}{5-4 \mu_{1}}$

$$
D_{3}=\frac{\bar{\theta} \bar{\alpha}^{3}}{6144 \mu_{1}(\bar{\alpha}+\bar{\theta})^{2}}\left[3072 \mu_{1}\left(1-2 \mu_{1}\right)+256 \mu_{1}\left(19-23 \mu_{1}\right) \delta+8 \mu_{1}\left(119-108 \mu_{1}\right) \delta^{2}+7\left(5-4 \mu_{1}\right)^{2} \delta^{3}\right]
$$

Case 4: $\mu_{1}>\frac{5}{6}$ and $\frac{4 \mu_{1}}{5-4 \mu_{1}}<\delta<\frac{6 \mu_{1}}{5-4 \mu_{1}}$

$$
D_{4}=\frac{\bar{\theta} \bar{\alpha}^{3}}{1536 \mu_{1}(\bar{\alpha}+\bar{\theta})^{2}}\left[768 \mu_{1}\left(1-2 \mu_{1}\right)+4 \mu_{1}\left(304-371 \mu_{1}\right) \delta+4 \mu_{1}\left(67-60 \mu_{1}\right) \delta^{2}+\left(5-4 \mu_{1}\right)^{2} \delta^{3}\right]
$$

Case 5: $\mu_{1}>\frac{5}{6}$ and $\delta>\frac{6 \mu_{1}}{5-4 \mu_{1}}$

$$
D_{5}=\frac{\bar{\theta} \bar{\alpha}^{3}}{24(\bar{\alpha}+\bar{\theta})^{2}}\left[12\left(1-2 \mu_{1}\right)+\left(19-26 \mu_{1}\right) \delta+\left(7-6 \mu_{1}\right) \delta^{2}\right]
$$

Case 6: $\frac{1}{2}<\mu_{1}<\frac{5}{6}$ and $\delta<\frac{4}{5} \mu_{1}$

$$
D_{6}=\frac{\bar{\theta} \bar{\alpha}^{3}}{93(\bar{\alpha}+\bar{\theta})^{2}}\left[48\left(1-2 \mu_{1}\right)-12\left(-8+9 \mu_{1}\right) \delta+\left(13-12 \mu_{1}\right) \delta^{2}+7\left(-5+4 \mu_{1}\right) \delta^{3}\right]
$$

Case 7: $\frac{1}{2}<\mu_{1}<\frac{5}{6}$ and $\frac{4}{5} \mu_{1}<\delta<\frac{6}{5} \mu_{1}$

$D_{7}=\frac{\bar{\theta} \bar{\alpha}^{3}}{6144 \mu_{1}(\bar{\alpha}+\bar{\theta})^{2}}\left[-3072\left(-1+2 \mu_{1}\right)+16 \mu_{1}\left(384-473 \mu_{1}\right) \delta-216 \mu_{1}\left(-7+4 \mu_{1}\right) \delta^{2}+\left(175-2120 \mu_{1}+1792 \mu_{1}^{2}\right) \delta^{3}\right]$

Case 8: $\frac{1}{2}<\mu_{1}<\frac{5}{6}$ and $\frac{6}{5} \mu_{1}<\delta<\frac{4 \mu_{1}}{5-4 \mu_{1}}$

$D_{8}=\frac{\bar{\theta} \bar{\alpha}^{3}}{18432 \mu_{1}(\bar{\alpha}+\bar{\theta})^{2}}\left[-9216 \mu_{1}\left(-1+2 \mu_{1}\right)-768 \mu_{1}\left(-24+41 \mu_{1}\right) \delta+24 \mu_{1}\left(139-180 \mu_{1}\right) \delta^{2}+7\left(175-840 \mu_{1}+768 \mu_{1}^{2}\right) \delta^{3}\right]$

Case 9: $\frac{1}{2}<\mu_{1}<\frac{5}{6}$ and $\frac{4 \mu_{1}}{5-4 \mu_{1}}<\delta<\frac{6 \mu_{1}}{5-4 \mu_{1}}$

$D_{9}=\frac{\bar{\theta} \bar{\alpha}^{3}}{2304 \mu_{1}(\bar{\alpha}+\bar{\theta})^{2}}\left[-1152 \mu_{1}\left(-1+2 \mu_{1}\right)-6 \mu_{1}\left(-384+659 \mu_{1}\right) \delta-6 \mu_{1}\left(-77+96 \mu_{1}\right) \delta^{2}+\left(125-690 \mu_{1}+654 \mu_{1}^{2}\right) \delta^{3}\right]$

Case 10: $\frac{1}{2}<\mu_{1}<\frac{5}{6}$ and $\frac{6 \mu_{1}}{5-4 \mu_{1}}<\delta<\frac{4 \mu_{1}}{5-6 \mu_{1}}$

$D_{10}=\frac{\bar{\theta} \bar{\alpha}^{3}}{4608 \mu_{1}(\bar{\alpha}+\bar{\theta})^{2}}\left[2304 \mu_{1}\left(-3+2 \mu_{1}\right)+768 \mu_{1}\left(-18+13 \mu_{1}\right) \delta+24 \mu_{1}\left(-323+318 \mu_{1}\right) \delta^{2}+35\left(5-36 \mu_{1}+36 \mu_{1}^{2}\right) \delta^{3}\right]$

Case 11: $\frac{1}{2}<\mu_{1}<\frac{5}{6}$ and $\frac{4 \mu_{1}}{5-6 \mu_{1}}<\delta<\frac{6 \mu_{1}}{5-6 \mu_{1}}$

$D_{11}=\frac{\bar{\theta} \bar{\alpha}^{3}}{1152 \mu_{1}(\bar{\alpha}+\bar{\theta})^{2}}\left[-576 \mu_{1}\left(-1+2 \mu_{1}\right)-36 \mu_{1}\left(-32+59 \mu_{1}\right) \delta+36 \mu_{1}\left(11-14 \mu_{1}\right) \delta^{2}+5\left(5-36 \mu_{1}+36 \mu_{1}^{2}\right) \delta^{3}\right]$

Case 12: $\frac{1}{2}<\mu_{1}<\frac{5}{6}$ and $\delta>\frac{6 \mu_{1}}{5-6 \mu_{1}}$

$$
D_{12}=\left(\mu_{1}-\frac{1}{2}\right) \bar{\alpha} \bar{\theta}>0
$$

